\section{MELIOLACEOUS FUNGI ON ECONOMICALLY IMPORTANT PLANTS IN INDIA - II: ON PLANTS OF NON-WOOD FOREST PRODUCE}

\author{
V.B. Hosagoudar
}

Microbiology Division, Tropical Botanic Garden and Research Institute, Palode, Thiruvananthapuram, Kerala 695562, India Email:vbhosagoudar@rediffmail.com

We have reached a stage to utilize and conserve our natural resources in sustainable and skilful manner. Hence, it is urgent and important to evaluate our biodiversity. Fungi form an object of the present study.

\section{Importance of the study of fungi}

1. The documentation of fungi provides a base for monitoring success of conservation and management practices.

2. Effective control measures can be only if we have the knowledge about the plant and animal diseases caused by the fungi

3. Biological control of weeds can be monitored

4. Biological control of arthropods in paddy fields can be implemented

5. Medicinal properties of new, virulent and genetically well establized organisms can be brought for the welfare

6. Quarantine will be effective and successful

7. Role of fungi in nutrient cycling and ecosystem management

8. Basic resource for the biotechnology

9. Utility of mycotoxin producing members

10. For the use of pure science.

There are numerous undiscovered fungi that have the genetic potential to produce a multitude of novel compounds. Fungi have aquired different mode of nutritional habitat. The present study has been restricted here only to the meliolaceous fungi on the non-wood forest produce yielding plants and the data is based on Meliolales of India (Hosagoudar, 1996) and the subsequent work. The plants are classified under different categories based on the data provided by Nayar et al. (1989) and Nair (2000).

\section{Enumeration of species}

1. Amazonia syzygii Hosag. in Hosag. \& Goos, Mycotaxon 36: 236, 1989; 42:126, 1991; Hosag., Dayal \& Goos, Mycotaxon 46: 202,1993; Hosag., Meliolales of India, p.74, 1996

Materials examined: On leaves of Syzygium cumini Skeels (Myrtaceae), Idukki, Kerala, 13.xii.1992, V.B. Hosagoudar HCIO 40469 (type); Shankarankudi, Valparai, Coimbatore, Tamil Nadu, 27.xii.1990, V.B. Hosagoudar HCIO 30514; Syzygium sp., Sampaje forest nursery, Sampaje, Kodagu, Karnataka, 22.xii.1991, B.R. Dayal HCIO 30841.

Colonies amphigenous, subdense, crustose to slightly velvety, up to $2 \mathrm{~mm}$ in diameter, rarely confluent. Hyphae substraight to slightly undulate, branching mostly opposite at wide angles, closely reticulate, cells $16-20 \times 6-8 \mu \mathrm{m}$. Appressoria alternate, straight, antrorse to spreading, $18-20 \mu \mathrm{m}$ long; stalk cells cylindrical to cuneate, $4-8 \mu \mathrm{m}$ long; head cells ovate to subglobose, entire, $10-14 \times 8-10 \mu \mathrm{m}$. Phialides mixed with appressoria, opposite to alternate, conoid to ampulliform, 20$24 \times 8-10 \mu \mathrm{m}$. Perithecia flattened-globose, scattered to grouped, up to $180 \mu \mathrm{m}$ in diam.; ascospores obovate, 4-septate, slightly constricted, $44-48 \times 16-20 \mu \mathrm{m}$.

Host range: Syzygium spp.

Distribution: India

2. Armatella balakrishnanii Hosag., J. Econ. Taxon. Bot. 15: 196, 1991.

Materials examined: On leaves of Cinnamomum malabatrum (Burm.f.) Blume (Lauraceae), Idukki, Kerala, India, 18.iv.1982, V.B. Hosagoudar MH 72696; Kombe, Thiruvananthapuram, Kerala, 11.iii.1996, V.B. Hosagoudar HCIO 43982, TBGT 409; Kombe, Thiruvan-anthapuram, Kerala, 11.iii.1996, V.B. Hosagoudar HCIO 44016, TBGT 410.

Colonies hypophyllous, thin, spreading, up to $8 \mathrm{~mm}$ in diameter. Hyphae smooth walled, crooked, branching alternate to irregular at acute angles, closely reticulate, cells 9-25 x 4.5-6.5mm. Appressoria alternate, antrorse to reflexed, 15.5-115mm long; stalk cells aseptate to several septate, straight to tortuous, 3$102.5 \mathrm{~mm}$ long; head cells globose, narrowly ovate, angular, entire, 9-12.5 x 10-12mm. Perithecia scattered, globose, verrucose, up to $115 \mathrm{~mm}$ in diam.; ascospores ellipsoidal, mostly aseptate but few ascospores septate, cells unequal, 43.5-49.5 x 18.5-21.5mm.

Host range: Cinnamomum malabatrum Distribution: India

3. Armatella cinnamomicola Hansf., Reinwardtia 3: 87, 1954; Hosag. \& Goos, Mycotaxon 36: 237, 1989; Hosag., J. Econ. Taxon. Bot. 15: 197, 1991.

Materials examined: On leaves of Cinnamomum malabatrum (Burm.f.) Blume (Lauraceae), Idukki, Kerala, India, 18.iv.1982, V.B. Hosagoudar MH 72696, HCIO 39302; on C. macrocrpum Hook. f., MPCA, Kulamavu, Idukki, Kerala, 5.ix.2001, M. Kamarudeen HCIO 44881, TBGT 572; on Cinnamomum sp., Sylven valley Hills, Munnar, Idukki, Kerala, 25.iv.2002, S. Shiburaj HCIO 44548, TBGT 834.

Colonies epiphyllous, thin to subdense, crustose, up to $4 \mathrm{~mm}$ in diameter, confluent. Hyphae crenulated, straight to substraight, branching alternate to irregular at acute angles, loosely reticulate, cells $15-40$ x $6.5-9 \mathrm{~mm}$, outer wall crenulated except the growing tips. Appressoria alternate, antrorse to spreading, straight to curved, $16-23 \mathrm{~mm}$ long; stalk cells cylindrical to cuneate, 4-6mm long; head cells ovate, broadly conoid, rarely globose, 13-20 x 8-13mm, outer wall crenulated. Perithecia seated on tortuous exappressoriate mycelia, scattered, globose, up to $215 \mathrm{~mm}$ in diameter; ascospores initially hyaline,

(C) Zoo Outreach Organisation; www.zoosprint.org Manuscript 1493; Received 02 January 2006; Finally accepted 28 June 2006; Date of publication 21 July 2006 


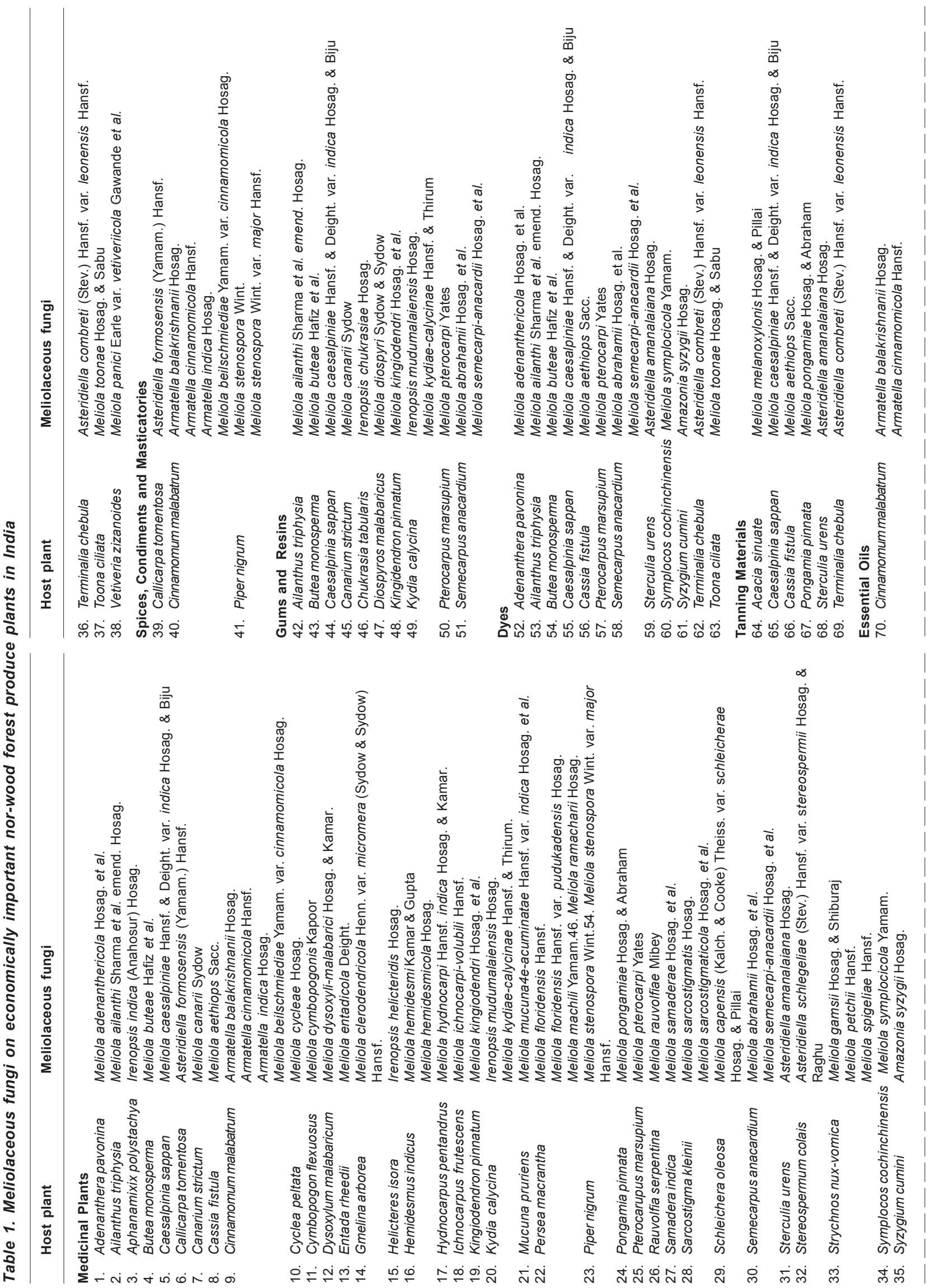




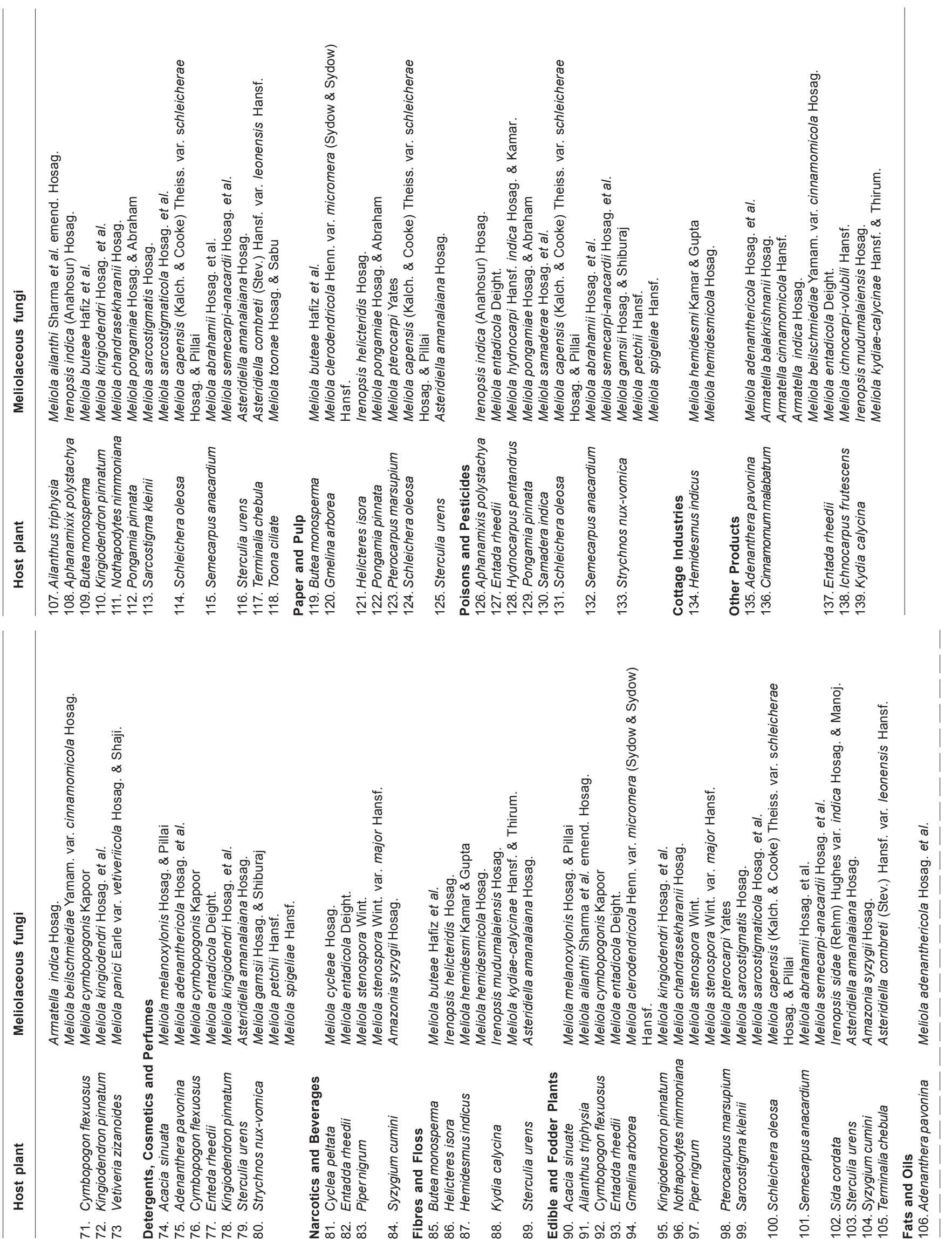


Key to the genera of meliolaceous fungi

$\begin{array}{ll}\text { 1. } & \text { Perithecia flattened-globose in radiating cells } \\ \text { Perithecia globose and not in radiating cells } \ldots \ldots \ldots \ldots \ldots \ldots\end{array}$

continuous, oblong with rounded ends, dumbell shaped, mature ascospore 1-septate with mostly equal cells, cinnamon brown to dark brown, 23-30 x 10-13mm, germinating cells enlarge to form appressoria and the other one empties and collapses.

Host range: Cinnamomum spp.

Distribution: Asia

4. Armatella indica Hosag., J. Econ. Taxon. Bot. 15: 199, 1991.

Materials examined: On leaves of Cinnamomum malabatrum (Burm. f.) Blume, Idukki, Kerala, India, 5.x.1983, V.B. Hosgoudar MH 78160

Colonies hypophyllous, carbonaceous black, dense, velvety, up to $5 \mathrm{~mm}$ in diameter. Hyphae smooth walled, crooked, branching alternate to irregular at acute angles, closely reticulate, cells $12.5-31 \times 6-9.5 \mathrm{~mm}$. Appressoria alternate, about $5 \%$ opposite, antrorse to spreading, $15.5-21.5 \mathrm{~mm}$ long; stalk cells single celled, cylindrical to cuneate, $6-9.5 \mathrm{~mm}$ long; head cells ovate, globose, angular, rarely lobate, $9-12.5 \times 12.5-15.5 \mathrm{~mm}$. Perithecia scattered, verrucose, up to $310 \mathrm{~mm}$ in diam.; ascospores initially aseptate, one septate at maturity, brown, $46.5-52.5$ x $18.5-21.5 \mathrm{~mm}$

Host range: Cinnamomum malabatrum

Distribution: India

5. Asteridiella anamalaiana Hosag. in Hosag. \& Goos, Mycotaxon 42: 127, 1991, Hosag., Meliolales of India, p81, 1996

Materials examined: On leaves of Sterculia urens Roxb. (Sterculiaceae), Nedungundru, Valparai, Veloniae, Coimbatore, Tamil Nadu, 23.xii.1990, V.B. Hosagoudar HCIO 30529 (type) (as Meliola anamalaiana).

Colonies epiphyllous scattered, dense, crustose to velvety, up to $2 \mathrm{~mm}$ in diameter. Hyphae substraight to crooked, branching opposite to irregular at acute angles, loosely to closely reticulate, cells $24-28$ x 6-8 $\mu \mathrm{m}$. Appressoria alternate, mostly antrorse, 21 $28 \mu \mathrm{m}$ long; stalk cells cylindrical to cuneate, $6-9.5 \mu \mathrm{m}$ long; head cells globose, angular to rarely sublobate, $15-18$ x $18-22 \mu \mathrm{m}$. Phialides numerous, mixed with appressoria, opposite to alternate, ampulliform, 18-22 x 6-9.5 $\mu \mathrm{m}$. Perithecia scattered, up to $140 \mu \mathrm{m}$ in diameter; perithecial cells protruded, conoid, curved at the apex, up to $15 \mu \mathrm{m}$ long; ascospores obovoidal to cylindrical, 4-septate, slightly constricted at the septa, 43-53 x
$18-22 \mu \mathrm{m}$

Host range: Sterculia urens

Distribution: India

6. Asteridiella combreti (Stev.) Hansf. var. leonensis Hansf., Sydowia Beih. 20: 160, 1961; Hosag. \& Goos, Mycotaxon 36: 238, 1989, Hosag., Meliolales of India, p 83, 1996.

Materials examined: On leaves of Terminalia chebula Retz. (Combretaceae), Radhanagari, Maharashtra, x.1971, A.N. Thite HCIO 31914; T. paniculata Roth, Idukki, Kerala, 13.xii.1982, V.B. Hosagoudar HCIO 40476, MH 75727; 24.i.1983, V.B. Hosagoudar MH 75824; Meenmutty, Kerala, 27.xii.1983, V.B. Hosagoudar MH 78990; 4.x.1983, V.B. Hosagudar MH 78142; Chinnar, Munnar, Idukki, Kerala, 6.i.1999, C.K. Buju TBGT 906; TBGRI campus, Palode, Thiruvananthapuram, Kerala, 3.i.2001, H. Biju HCIO 44562, TBGT 849, on Terminalia sp., TBGRI campus, Palode, Thiruvananthapuram, Kerala, 20.i.2001, H. Biju HCIO 44575, TBGT 862.

Colonies epiphyllous, subdense, up to $4 \mathrm{~mm}$ in diameter, confluent. Hyphae substraight to slightly undulate, branching alternate to opposite at wide angles, loosely reticulate, cells 20$34 \times 6-8 \mu \mathrm{m}$. Appressoria alternate, straight, antrorse, $20-26 \mu \mathrm{m}$ long; stalk cells cylindrical to cuneate, $6-8 \mu \mathrm{m}$ long; head cells globose, entire to angular, 12-18 x 12-16 $\mu \mathrm{m}$. Phialides numerous, borne on a separate mycelial branch, opposite, ampulliform, 14$24 \times 4-8 \mu \mathrm{m}$, tip occasionally twisted and bent variously. Perithecia scattered, verrucose, up to $170 \mu \mathrm{m}$ in diam.; perithecial cells mammillate, $8-10 \mu \mathrm{m}$ long; ascospores obovoidal, 4-septate, constricted, $36-42 \times 12-18 \mu \mathrm{m}$.

Host range: Terminalia spp.

Distribution: India

7. Asteridiella formosensis (Yamam.) Hansf., Sydowia 10: 48, 1957; Sydowia Beih. 2:686, 1961; Hosag. \& Goos, Mycotaxon 36: 240, 1989; 42: 128, 1991; Hosag., Kaveriappa, Raghu \& Goos, Mycotaxon 51:109, 1994, Hosag., Meliolales of India, p90,1996. Irene formosensis Yamam., Trans. Nat. Hist. Soc. Taiwan 31: 15, 1941.

Meliola formosensis (Yamam.) Cif., Mycopathologia 7: 87, 1954 (non Yamam, 1941).

Materials examined: On leaves of Callicarpa tomentosa (L.) Murray (Verbenaceae), Idukki, Kerala, 4.x.1983, V.B. Hosagoudar 
MH 78157; Pamba, Kerala, 10.x.1983, V.B. Hosagoudar MH 78929; Castle Rock, Karnataka, 1.i.1984, C.R. Patil HCIO 40031; 10.i.1984, C.R. Patil HCIO 30803; Kozhikamathi, Top Slip, Coimbatore, Tamil Nadu, 21.xii.1990, V.B. Hosagoudar HCIO 30517; Gersoppa, Uttar Kannada, Karnataka, 25.x.1992, P.A. Raghu HCIO 40856; Radhanagari, Maharashtra, 1981, A.N. Thite HCIO 31631; Zolambi, Chandoli, Sangli, Maharashtra, 29.iii.1991, C.R. Patil HCIO 30803; Veerapuli Reserve Forest, Kanniyakumari dist., Tamil Nadu, 22.ii.1994, V.B. Hosagoudar HCIO 41643.

Colonies epiphyllous, thin, smooth, up to $4 \mathrm{~mm}$ in diameter, confluent. Hyphae substraight to undulate, branching alternate at wide angles, loosely reticulate, cells 30-44 x 6-8 $\mu \mathrm{m}$. Appressoria alternate, straight to curved, antrorse, spreading, 26-36 $\mu \mathrm{m}$ long; stalk cells cuneate to cylindrical, $8-12 \mu \mathrm{m}$ long; head cells ovate, clavate, entire to sublobate, $18-24$ x 12-16 $\mu \mathrm{m}$. Phialides borne on a separate mycelial branch, mostly opposite, rarely unilateral, often two phialides borne very closely to a single mycelial cells, ampulliform, 12-18 x 6-8 $\mu \mathrm{m}$. Perithecia scattered, up to $200 \mu \mathrm{m}$ in diam.; perithecial cells obtusely conoid, 6-10 $\mu \mathrm{m}$ long; ascospores ellipsoidal, 4-septate, constricted, middle cell slightly larger, $42-46$ x 20-26 $\mu \mathrm{m}$.

Host range: Callicarpa tomentosa

Distribution: India

8. Asteridiella schlegeliae (Stev.) Hansf. var. stereospermi Hosag. \& Raghu in Hosag., Raghu \& Pillai, Nova Hedwigia 58: 531, 1994, Hosag., Meliolales of India, p102, 1996.

Materials examined: On leaves of Stereospermum colais (Buch.Ham. ex Dillwyn.) Mabb. (Bignoniaceae), Gersoppa, Uttara Kannada, Karnataka, May 24, 1992, P.A. Raghu HCIO 40749 (type).

Colonies amphigenous, dense, crustose, up to $3 \mathrm{~mm}$ in diameter. Hyphae straight to substraight, branching alternate to opposite at acute angles, closely reticulate, cells $12-22 \times 6-9.5 \mu \mathrm{m}$. Appressoria alternate, straight to variously curved, antrorse, 21-31 $\mu \mathrm{m}$ long; stalk cells cylindrical to cuneate, $6-15.5 \mu \mathrm{m}$ long; head cells ovate, globose, mostly sublobate, rarely entire to angular, $15-18.5 \times 12-15.5 \mu \mathrm{m}$. Phialides mixed with appressoria, alternate to opposite, ampulliform, $18-21.5 \times 6-7 \mu \mathrm{m}$. Perithecia scattered, up to $124 \mu \mathrm{m}$ in diam; perithecial cells conoid to mammiform, straight to curved, up to $25 \mu \mathrm{m}$ long; ascospores obovoidal, 4-septate, slightly constricted, 40-43.5 x 18-22 $\mu \mathrm{m}$.

Host range: Stereospermum colais

Distribution: India

9. Irenopsis chukrasiae Hosag. in Hosag., Raghu \& Pillai, Nova Hedwigia 58: 532, 1994; Hosag., Meliolales of India, p. 109, 1996.

Materials examined: On leaves of Chukrasia tabularis A. Juss. (Meliaceae), North to Pachaiyar Estate, Seithur Hills, Kamarajar dist., Tamil Nadu, 9.ix.1992, V.B. Hosagoudar HCIO 40750 (type).
Colonies hypophyllous, subdense to dense, strongly appressed to the lead, up to $4 \mathrm{~mm}$ in diameter, rarely confluent. Hyphae subst5raight to crooked, branching alternate to irregular at acute angles, closely reticulate, cells 24-31 x 6-9.5 $\mu \mathrm{m}$. Appressoria closely to distantly placed, alternate, straight, curved to flexuous, antrorse to recurved, $18-46.5 \mu \mathrm{m}$ long; stalk cells cylindrical to cuneate, straight to flexuous, 1-3 celleed, $6-34 \mu \mathrm{m}$ long; head cells ovate, globose, angular to sublobate to deeply lobate, $9-15.5 \times 12-18.5 \mu \mathrm{m}$. Phialides borne on a separate mycelial branch, alternate to opposite, ampulliform, 21-25 x 5$7 \mu \mathrm{m}$. Perithecia scattered, verrucose, up to $210 \mu \mathrm{m}$ in diam.; perithecial setae 5-12, erect to prostrate, simple, straight, acute to obtuse at the tip, bulbous qat the base, up to $110 \mu \mathrm{m}$ long; ascospores oblong, obovate, 4-septate, 40-46.5 x 15-18.5 $\mu \mathrm{m}$.

\section{Host range: Chukrasia tabularis}

Distribution: India

10. Irenopsis helicteridis Hosag., Crypt. Bot. 2/3: 184, 1991; Hosag., Meliolales of India, p. 111, 1996.

Materials examined: On leaves of Helicteres isora L. (Sterculiaceae), Sri Madurai, Nilgiris, Tamil Nadu, 25.i.1990, V.B. Hosagoudar HCIO 30358 (type); Kombe, Meenmutty, Thiruvananthapuram, Kerala, 9.iv.1996, V.B. Hosagoudar HCIO 42146, TBGT 10; Kombe, Meenmutty, Thiruvananthapuram, Kerala, 19.ii.1997, V.B. Hosagoudar TBGT 188.

Colonies epiphyllous, densee, up to $2 \mathrm{~mm}$ in diameter. Hyphae tortuous, branching irregular at acute angles, closely to loosely reticulate, cells $24-40$ x $6-9 \mu \mathrm{m}$ long; stalk cells cylindrical to cuneate, 3-15.5 $\mu \mathrm{m}$ long; head cells ovate, globose, versiform, angular, truncate to slightly lobate, $12-15.5 \times 15.5-19 \mu \mathrm{m}$. Phialides mixed with appressoria, opposite to alternate, ampulliform, 40-46.5 x 12-15.5 $\mu \mathrm{m}$. Perithecia scattered, globose, up to $175 \mu \mathrm{m}$ in diam.; perithecial setae $4-10$, straight to curved, obtuse, up to $120 \mu \mathrm{m}$ long; ascospores obovoidal, 4-septate, constricted, $31-40.5 \times 12-15.5 \mu \mathrm{m}$.

\section{Host range: Helicteres isora}

Distribution: India

11. Irenopsis indica (Anahosur) Hosag., J. Econ. Tax. Bot. 6:250, 1985. 250, 1985; Hosag., Meliolales of India, p. 111, 1996.

Irene indica Anahosur, Sydowia 23:58, 1970.

Materials examined: On leaves of Aphanamixis polystachya (Wall.) Parker [Amoora rohituka (Roxb.) Wight \& Arn.] (Meliaceae), Coorg, Karnataka, 17.x.1967, K.H. Anahosur AMH 620 (type).

Colonies hypophyllous, subdense to dense, scattered, up to 3 $\mathrm{mm}$ in diameter. Hyphae crooked, branching irregular at acute to wide angles, loosely reticulate, cells $24-37$ x $6-9.5 \mu \mathrm{m}$. Appressoria alternate, distantly arranged, straight to variously curved, 15-18.5 $\mu \mathrm{m}$ long; stalk cells cuneate to cylindrical, 3$6.5 \mu \mathrm{m}$ long; head cells ovate, entire to angular, 9.5-12.5 x 12.5$15.5 \mu \mathrm{m}$. Phialides few, mixed with appressoria, alternate, 
ampulliform, 18.5-25 x 9-12.5 $\mu \mathrm{m}$. Perithecia mostly grouped, up to $233 \mu \mathrm{m}$ in diam.; perithecial setae $10-15$, straight, simple, septate, acute to obtuse at the tip, 108-140 x 6-9.5 $\mu \mathrm{m}$; ascospores obovoidal, 4-septate, constricted, 40-43.5 x 18.5-22 $\mu \mathrm{m}$.

Host range: Aphanamixis polystachya

Distribution: India

12. Irenopsis mudumalaiensis Hosag., Crypt. Bot. 2/3: 184, 1991 (mudumalaiense); Hosag., Meliolales of India, p. 114, 1996.

Materials examined: On leaves of Kydia calycina Roxb. (Malvaceae), Sri Madurai, Nilgiris, Tamil Nadu, 24.i.1990, V.B. Hosagoduar HCIO 30359 (type).

Colonies epiphyllous, subdense, up to $3 \mathrm{~mm}$ in diameter, confluent. Hyphae flexuous to tortuous, branching alternate to irregular at acute angles, loosely reticulate, cells 34-37 x 6$9.5 \mu \mathrm{m}$. Appressoria alternate, scattered, mostly antrorse, 15$28 \mu \mathrm{m}$ long; stalk cells cylindrical to cuneate, 6-9.5 $\mu \mathrm{m}$ long; head cells globose, ovate, entire to slightly angulose, 9-15.5 x 12$15.5 \mu \mathrm{m}$. Phialides borne on a separate mycelial branch, alternate to opposite, ampulliform, $18-28 \times 6-9 \mu \mathrm{m}$. Perithecia scattered, verrucose, up to $140 \mu \mathrm{m}$ in diameter; perithecial setae 4-10, straight to curved, dark, obtuse at apex, up to $110 \mu \mathrm{m}$ long; ascospores obovoidal, mostly cylindrical, 4-septate, 37-40.5 x $15-18.5 \mu \mathrm{m}$.

Host range: Kydia calycina

Distribution: India

13. Irenopsis sidae (Rehm) Hughes var. indica Hosag. \& Manoj., Zoo's Print J. 18: 1000, 2003.

Materials examined: On leaves Sida cordata (Burm. f.) Borssum Waalkes (Malvaceae), Karikulam, Ranni, Pathanamthitta, Kerala, 9.x.2002, A. Manojkumar HCIO 44625 (type); TBGT 907 (isotype).

Colonies amphigenous, mostly epiphyllous, subdense to dense, up to $2 \mathrm{~mm}$ in diameter, confluent. Hyphae straight to flexuous, branching alternate, opposite to irregular at acute angles, loosely to closely reticulate, cells $22-29$ x 7-9 $\mu \mathrm{m}$. Appressoria alternate, about $5 \%$ opposite, antrorse, subantrorse to rarely retrorse, $14-18 \mu \mathrm{m}$ long; stalk cells cylindrical to cuneate, $3-6 \mu \mathrm{m}$ long; head cells ovate to globose, entire, angular to truncate at the apex, straight to curved, 9-13 x $8-10 \mu \mathrm{m}$. Phialides mixed with appressoria, alternate to opposite, ampulliform, 14-18 x 6$8 \mu \mathrm{m}$. Perithecia scattered, globose, perithecial cells slightly projected, perithecial setae 0-12 in numbers, simple, straight, acute at the apex, deep brown, septa not visible, up to $125 \mu \mathrm{m}$ long; ascospores oblong, 4-septate, slightly constricted at the septa, 30-32 x 11-13 $\mu \mathrm{m}$.

Host range: Sida cordata

Distribution: India
14. Meliola abrahamii Hosag., C.K. Biju \& Rajkumar, Zoos' Print J. 16: 595, 2001.

Materials examined: On leaves of (Anacardiaceae), Kerala, India, 26.x.2000, G. Rajkumar HCIO 43794, TBGT 394.

Colonies epiphyllous, dense up to $3 \mathrm{~mm}$ in diameter, confluent. Hyphae straight to slightly flexuous, branching mostly opposite at acute angles, loosely to closely reticulate, cells 24-32 x 8$10 \mu \mathrm{m}$. Appressoria alternate, antrorse to subantrorse, $28-40 \mu \mathrm{m}$ long; stalk cells cylindrical to cuneate, 6-16 $\mu \mathrm{m}$ long; head cells oblong, straight to curved, entire, angular to sublobate, 22-24 x 11-16 $\mu \mathrm{m}$. Phialides mixed with appressoria, alternate to opposite, ampulliform, 19-24 x 6-8 $\mu \mathrm{m}$. Mycelial setae scattered to grouped around perithecia, simple straight; setae around perithecia are few, acute obtuse, up to $300 \mu \mathrm{m}$ long; setae on mycelia are acute, up to $1200 \mu \mathrm{m}$ long. Perithecia scattered, up to $175 \mu \mathrm{m}$ in diameter; ascospores cylindrical, 4-septate, constricted, $46-50 \times 18-20 \mu \mathrm{m}$.

Host range: Semecarpus anacardium

Distribution: India

15. Meliola adenanthericola Hosag., Kamarudeen \& Babu in Hosag., C.K. Biju \& Abraham, J. Econ. Taxon. Bot. 25: 68, 2001.

Materials examined: On leaves of Adenanthera pavonia L. (Mimosaceae), Kerala, India, M. Kamarudeen \& K.P. Babu HCIO 43799, TBGT359; Vithura, Thiruvananthapuram, Kerala, 22.xi.2000, M. Kamarudeen HCIO 44123, TBGT 518; 3.xii.2000, M. Kamarudeen \& Babu HCIO 43799, TBGT 359;

Colonies amphigenous, mostly epiphyllous, dense up to $2 \mathrm{~mm}$ in diameter, confluent. Hyphae mostly crooked, rarely flexuous, branching alternate to opposite at acute to wide angles, loosely to closely reticulate, cells $18-25$ x $6-8 \mu \mathrm{m}$. Appressoria alternate, antrorse to spreading, $12-21 \mu \mathrm{m}$ long; stalk cells cylindrical to cuneate, $3-10 \mu \mathrm{m}$ long; head cells predominantly globose, often oblong to cylindrical, straight to curved, entire, 9-11 x 8-10 $\mu \mathrm{m}$. Phialides mixed with appressoria, alternate to opposite, ampulliform, 19-24 x 8-10 $\mu$ m. Mycelial setae scattered to grouped around perithecia, simple, straight, acute to obtuse at the tip, up to $345 \mu \mathrm{m}$ long. Perithecia scattered, up to $125 \mu \mathrm{m}$ in diameter; ascospores cylindrical to slightly fusiform, 4-septate, constricted, 35-39 x 12-15 $\mu \mathrm{m}$.

Host range: Adenanthera pavonia

Distribution: India

16. Meliola aethiops Sacc., Biol. Orto Bot. Napoli 6: 41, 1921. Hansf., Sydowia Beih. 2: 252, 1961.

= Meliola javanica Cif., Mycopathologia 6: 19, 1951.

Materials examined: On leaves of Cassia fistula L. (Caesalpiniaceae), Eanikara, Karakulam, Thiruvananthapuram, Kerala, 15.i.2001, Mrs. H.V. Sharada HCIO 43742, TBGT 385; Karikulam, Ranni, Pathanamthitta, Kerala, 4.x.2002, A. Manojkumar HCIO, TBGT 899. 
Colonies amphigenous, subdense to dense, up to $2 \mathrm{~mm}$ in diameter, confluent and cover larger area on the lower surface. Hyphae straight to substraight, branching opposite at acute to wide angles, loosely to closely reticulate, cells $16-24$ x 4-6 $\mu \mathrm{m}$. Appressoria opposite, about $10 \%$ alternate, antrorse to subantrorse, 8-16 $\mu \mathrm{m}$ long; stalk cells cylindrical to cuneate, 3$5 \mu \mathrm{m}$ long; head cells ovate, entire, $4-11$ x 7-9 $\mu \mathrm{m}$. Phialides mixed with appressoria, alternate to opposite, ampulliform, 17-21 x 6$8 \mu \mathrm{m}$. Mycelial setae scattered to mostly grouped around perithecia, simple, straight, obtuse at the tip, up to $250 \mu \mathrm{m}$ long. Perithecia loosely grouped, up to $175 \mu \mathrm{m}$ in diameter; ascospores cylindrical to ellipsoidal, 4-septate, constricted at the septa, 35$40 \times 14-16 \mu \mathrm{m}$.

Host range: Cassia fistula

Distribution: India

17. Meliola ailanthi Sharma, Mohanan \& Florence, Kerala Forest Research Institute Report 36: 248, 1985 (ailanthii) emend. Hosag. in Hosag., Raghu \& Pillai, Nova

Hedwigia 58: 524, 1994; Hosag., Meliolales of India, p. 126, 1996.

Materials examined: On leaves of Ailanthus triphysa (Dennst.) Alston (Simaroubaceae), Vettiyar, Mavelikara, Kerala, India, 14.ix.1992, C.M. Pillai HCIO 40752; Ailanthus sp., Eanikara, Thiruvananthapuram, Kerala, 20.i.2001, V.B. Hosagoudar HCIO 43998, TBGT 427.

Colonies epiphyllous, scattered, dense, velvety, up to $2 \mathrm{~mm}$ in diameter. Hyphae straight, rarely substraight, branching mostly opposite at acute angles, loosely to closely reticulate, cells 24$31 \times 5-7 \mu \mathrm{m}$. Appressoria alternate, straight, antrorse, $15-22 \mu \mathrm{m}$ long; stalk cells cylindrical to cuneate, $5-7 \mu \mathrm{m}$ long; head cells ovate to cylindrical, entire, $10-15.5 \times 9-11 \mu \mathrm{m}$. Phialides mixed with appressoria, alternate to opposite, ampulliform, 18-22 x 9$12.5 \mu \mathrm{m}$. Mycelial setae numerous, straight to slightly curved but not uncinate, simple, acute to 2-3 dentate at the tip, up to $260 \mu \mathrm{m}$ long. Perithecia scattered to loosely grouped, verrucose, up to $172 \mu \mathrm{m}$ in diameter; ascospores obovoidal, 4-septate, constricted at the septa, 37-40.5 x 13-15.5 $\mu \mathrm{m}$.

Host range: Ailanthus triphysa

Distribution: India

18. Meliola beilschmiediae Yamam. var. cinnamomicola Hosag. in Hosag. \& Goos, Mycotaxon 87: 222, 1990; Hosag., Meliolales of India, p. 142, 1996.

Materials examined: On leaves of Cinnamomum malabatrum (Burm.f.) Blume (Lauraceae), Calvary Mount, Idukki, Kerala, 5.x.1983, V.B. Hosagoudar HCIO 34973 (type), MH 78160; Calvary Mount, Idukki, Kerala, 14.vi.1982, V.B. Hosagoudar MH 79012; Idukki, Kerala, 13.xii.1982, V.B. Hosagoudar MH 75741; Calvary Mount, Idukki, Kerala, 21.ii.1983, V.B. Hosagoudar MH 75833; Lakshmi Estate, Idukki, Kerala, 12.vi.1983, V.B. Hosagoudar MH 75081; Idukki, Kerala, 3.x.1983, V.B. Hosagoudar MH 78159; Pamba, Kerala, 11.x.1983, V.B. Hosagoudar MH
78940; Idukki, Kerala, 21.xii.1983, V.B. Hosagoudar MH 78970.

Colonies hypophyllous, dense, velvety, up to $3 \mathrm{~mm}$ in diameter, rarely confluent. Hyphae flexuous, branching alternate to irregular at acute angles, closely reticulate, form almost solid mycelial mat, cells 20-30 x 6-8 $\mu \mathrm{m}$. Appressoria alternate, straight

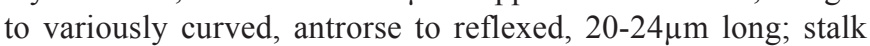
cells cylindrical to cuneate, $6-10 \mu \mathrm{m}$ long; head cells globose, ovate angular, entire, $14-16$ x 12-14 $\mu \mathrm{m}$. Phialides few, mixed with appressoria, opposite to alternate, ampulliform, 18-22 x 8$10 \mu \mathrm{m}$. Mycelial setae numerous, evenly scattered, straight, simple, acute to variously dentate at the tip, up to $684 \mu \mathrm{m}$ long. Perithecia closely scattered, verrucose, up to $216 \mu \mathrm{m}$ in diam.; ascospores obovoidal, 4-septate, slightly constricted, 54-60 x $16-20 \mu \mathrm{m}$.

Host range: Cinnamomum malabatrum

Distribution: India

19. Meliola buteae Hafiz, Azmatulla \& Kafi, Biologia 1: 112, 1955; Hansf., Sydowia Beih. 2: 291, 1961,; Thite \& Patil, Kavaka 10: 29, 1982; Hosag. \& Goos, Mycotaxon 37: 223, 1990; Hosag., Meliolales of India, p. 148, 1996.

Materials examined: On leaves of Butea monosperma (Lam.) Taub. (B. frondosa Roxb.) (Fabaceae), Radhanagari, Kolhapur, Maharashtra, 10.xi.1974, M.S. Patil HCIO 31940; Idukki, Kerala, 9.x.1982, V.B. Hosagoudar MH 73797; 4.x.1983, V.B. Hosagoudar MH 78145; B. parviflora Roxb., Vellakayam, Idukki, Kerala, 24.ii.1983, M. Ali \& C.N. Mohanan MH 75010; Kombe, Peppara and Neyyar Wildlife Sanctuary, Thiruvananthapuram, Kerala, 19.ii.1997, V.B. Hosagoudar HCIO 42518, TBGT 165;TBGRI arboretum, Palode, Thiruvananthapuram, Kerala, 5.ix.2002, Manojkumar \& H. Biju HCIO 44598, TBGT 885.

Colonies epiphyllous, subdense to dense, velvety, up to $4 \mathrm{~mm}$ in diameter, confluent. Hyphae substraight to crooked, branching opposite to irregular at wide angles, loosely to closely reticulate, cells $22-38 \times 6-8 \mu \mathrm{m}$. Appressoria alternate about 5\% opposite, antrorse, mostly spreading, straight to lcurved, 14$20 \mu \mathrm{m}$ long; stalk cells cylindrical to cuneate, $4-8 \mu \mathrm{m}$ long; head cells globose to subglobose, mostly curved, truncate, entire, 10-16 x 10-12 $\mu \mathrm{m}$. Phialides mixed with appressoria, alternate to opposite, ampulliform, 18-22 x 6-8 $\mu \mathrm{m}$. Mycelial setae mostly grouped around perithecia, straight, simple, acute to obtuse at the tip, up to $846 \mu \mathrm{m}$ long. Perithecia scattered to grouped, verrucose, up to $180 \mu \mathrm{m}$ in diam.; ascospores oblong, 4-septate, constricted, $40-48 \times 16-20 \mu \mathrm{m}$.

Host range: Butea spp.

Distribution: Asia

20. Meliola caesalpiniae Hansf. \& Deight. var. indica Hosag. \& H. Biju, J. Econ. Taxon. Bot. 25: 555, 2001.

Materials examined: On leaves of Caesalpinia sappan L. (Caesalpiniaceae), in the campus of TBGRI, Palode, Thiruvananthapuram, Kerala, 8.xi.2000, H. Biju HCIO 43686, 


\section{TBGT 355}

Colonies amphigenous, mostly epiphyllous, dense, up to $2 \mathrm{~mm}$ in diameter, often confluent. Hyphae substraight, branching mostly opposite at wide angles, loosely to closely reticulate, cells $19-23 \times 4-5 \mathrm{~mm}$. Appressoria alternate, up to $2 \%$ opposite, subantrorse, $12-16 \mathrm{~mm}$ long; stalk cells cylindrical to cuneate, 3-5 mm long; head cells ovate, globose, straight to curved, entire, 9-12 x 8-10 mm. Phialides mixed with appressoria, alternate to opposite, ampulliform, 12-16 x 6-8mm. Mycelial setae scattered, simple, straight, few curved, acute to obtuse at the tip, up to $345 \mathrm{~mm}$ long. Perithecia scattered, verrucose, up to $125 \mathrm{~mm}$ in diameter; ascospores oblong, 4-septate, constricted, $33-36$ x 11-13mm.

Host range: Caesalpinia sappan

Distribution: India

21. Meliola canarii Sydow, Ann. Mycol. 2: 550, 1914; Hansf., Sydowia Beih. 2: 399, 1961; Hosag., Dayal \& Goos, Mycotaxon 46: 204, 1993; Hosag., Meliolales of India, p. 150, 1996.

Meliola nigro-rufescens Sacc., Att. Acad. Ven.-Trent.-Istr. 10: 60, 1914.

Materials examined: On leaves of seedlings of Canarium strictum Roxb. (Burseraceae), Sampaje forest nursery, Sampaje, Kodagu, Karnataka, 22.xii.1991, B.R. Dayal HCIO 30838; Kakachi, Tirunelveli, Tamil Nadu, 23.ii.1994, V.B. Hosagoudar HCIO 41615.

Colonies epiphyllous, thin to thinly velvety, up to $5 \mathrm{~mm}$ in diameter, rarely confluent. Hyphae straight to flexuous, branching opposite at wide angles, loosely reticulate, cells 34$50 \times 6-8 \mu \mathrm{m}$. Appressoria alternate, less than $1 \%$ opposite, antrorse, 34-40.5 $\mu \mathrm{m}$ long; stalk cells cuneate, $6-12.5 \mu \mathrm{m}$ long; head cells ovate, tapered and broadly rounded but rarely truncate at the apex, entire, $24-285 \times 6-8 \mu \mathrm{m}$. Mycelial setae thinly scattered, simple, straight, acute to obtuse at the tip, up to $1050 \mu \mathrm{m}$ long. Perithecia scattered, globosoe, up to $140 \mu \mathrm{m}$ in diam.; ascospores obovoidal to cylindrical, 4-septate, slightly constricted at the septa, $43-46.5 \times 18-20 \mu \mathrm{m}$.

Host range: Canarium strictum

Distribution: Tropics

22. Meliola capensis (Kalch., \& Cooke) Theiss. var. schleicherae Hosag. \& Pillai in Hosag., Raghu \& Pillai, Nova Hedwigia 58: 583, 1994; Hosag., Meliolales of India, p. 157, 1996.

Materials examined: On leaves of Schleichera oleosa (Lour.) Oken (Sapindaceae), Vettiyar, Mavelikara, Kerala, 14.ix.1992, C.M. Pillai HCIO 40757 (type); Koomati, Anamalai, Coimbatore, Tamil Nadu, 13.iii.1994, V.B. Hosagoudar HCIO 41581; Kombe, Meenmutty, Peppara \& Neyyar Wildlife Sanctuary, Thiruvananthapuram, Kerala, 28.iii.1996, V.B. Hosagoudar 55; Sankili forest, Kollam, Kerala, 27.xii.2001, V.B. Hosagoudar TBGT 623; Lepisanthes erecta (Thw.) Leenh. (Sapindaceae), Sankili forest,
Kollam, Kerala, 27.xii.2001, V.B. Hosagoudar HCIO 44348, TBGT 643.

Colonies epiphyllous, rarely amphigenous, dense, velvety, up to $2 \mathrm{~mm}$ in diameter, confluent. Hyphae straight, branching opposite at acute angles, loosely to closely reticulate, cells 1525 x 6-7 $\mu \mathrm{m}$. Appressoria opposite, crowded to sparse, $9-15.5 \mu \mathrm{m}$ long; stalk cells cuneate, $3-5 \mu \mathrm{m}$ long; head cells conoid, rarely broadly rounded at the apex, entire, $6-11 \times 6-9.5 \mu \mathrm{m}$. Phialides mixed with appressoria, alternate to opposite, ampulliform, 12$15.5 \times 6-9.5 \mu \mathrm{m}$. Mycelial setae scattered, straight, acute to dentate at the tip, up to $320 \mu \mathrm{m}$ long. Perithecia scattered, verrucose, up to $155 \mu \mathrm{m}$ in diam.; ascospores obovoidal, 4septate, slightly constricted, $30-35$ x 12-15.5 $\mu \mathrm{m}$.

Host range: Schleichera oleosa, Lepisanthes erecta Distribution: Tropics

23. Meliola chandrasekharanii Hosag. in Hosag. \& Goos, Mycotaxon 37: 225, 1990; 42: 133, 1991; Hosag., Meliolales of India, p. 164, 1996.

Materials examined: On leaves, stems and petioles of Apodytes dimidiata E. Meyer ex Arn. (Icacinaceae), Lakshmi Estate, Idukki, Kerala, 15.xii.1982, V.B. Hosagoudar MH 79089; 20.x.2000, M. Kamarudeen HCIO 43983, TBGT 478; on Apodytes sp., Kannimala Estate, Munnar, Kerala, 20.xii.2001, S. Shiburaj HCIO 44349, TBGT 705; on Notopodytes nimmoniana (Graham) Mabberly, Shankarankudi, Valparai, Coimbatore, Tamil Nadu, 27.xii.1990, V.B. Hosagoudar HCIO 30538; Mahabaleshwar, Maharashtra, ii.1977, V.P. Kaul HCIO 33811; Bhagamandala, Karnataka, 1.iii.1984, C.R. Patil HCIO 40004; Veerapuli Reserve Forest, Kanniyakumari, Tamil Nadu, 22.ii.1994, V.B. Hosagoudar HCIO 41532.

Colonies amphigenous, caulicolous, mostly hypophyllous, subdense, velvety, up to $3 \mathrm{~mm}$ diameter, confluent. Hyphae undulate, branching opposite at acute angles, loosely to closely reticulate and form almost solid mycelial mat, cells $16-30 \times 6$ $8 \mu \mathrm{m}$. Appressoria alternate (few opposite), straight to curved, spreading, mostly antrorse, 16-24 $\mu \mathrm{m}$ long; stalk cells cuneate to cylindrical, $4-10 \mu \mathrm{m}$ long; head cells subglobose, ovate, angular to sublobate, $12-16 \times 14-16 \mu \mathrm{m}$. Phialides borne on a separate mycelial branch and also few mixed with appressoria, alternate, mostly opposite, ampulliform, 12-20 x 6-10 $\mu \mathrm{m}$. Mycelial setae fairly numerous, straight, simple, acute to subacute at the tip, up to $477 \mu \mathrm{m}$ long. Perithecia scattered, verrucose, up to $153 \mu \mathrm{m}$ in diam.; ascospores obovoidal to cylindrical, 4-septate, $32-42 \times 10-16 \mu \mathrm{m}$.

Host range: Apodytes spp., Notopodytes nimmoniana Distribution: India

24. Meliola clerodendricola Henn. var. micromera (Sydow \& Sydow) Hansf., Sydowia Beih. 2: 694, 1961; Hosag. \& Goos, Mycotaxon 37: 227, 1990; Hosag., Meliolales of India, p. 170, 1996.

Meliola micromera Sydow, Ann. Mycol. 12: 552, 1914. 
Materials examined: On leaves of Gmelina arborea Roxb. (Verbenaceae), Meenmutty, Idukki, Kerala, 12.xii.1982, V.B. Hosagoudar HCIO 40511, MH 73690; near Painavu, Idukki, Kerala, 12.xii.1983, V.B. Hosagoudar MH 78979; 3.x.1983, V.B. Hosagoudar MH 78126; G. asiatica L., Mundandurai, Tamil Nadu, 7.xii.1987, A. Rajendran HCIO 39285; Peppara, Thiruvananthapuram, Kerala, 20.ii.1997, V.B. Hosagoudar HCIO 44070, TBGT 503; in the campus of TBGRI, Thiruvananthapuram, Kerala, 7.xii.2001, H. Biju HCIO 44467, TBGT 757; 7.xii.2001, H. Biju 44468, TBGT 793.

Colonies epiphyllous, subdense, velvety, up to $2 \mathrm{~mm}$ in diameter, confluent. Hyphae straight to sinuous, branching opposite at acute angles, loosely to closely reticulate, cells $18-34$ x 6-8 $\mu \mathrm{m}$. Appressoria alternate, antrorse, rarely spreading, mostly

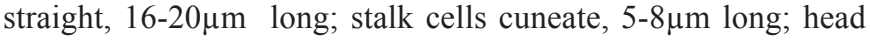
cells ovate, globose, entire, 11-14 x 10-12 $\mu \mathrm{m}$. Phialides numerous, mixed with appressoria, opposite to alternate, ampulliform, 12-20 x 6-10 $\mathrm{m}$. Mycelial setae few, grouped around perithecia, straight, simple, obtuse at the tip, up to $190 \mu \mathrm{m}$ long. Perithecia scattered, up to $189 \mu \mathrm{m}$ in diameter; ascospores oblong, 4-septate, constricted, 30-32 x 10-14 $\mu \mathrm{m}$.

Host range: Gmelina arborea

Distribution: Asia

25. Meliola cycleae Hosag. in Hosag. \& Goos, Mycotaxon 37 : 228, 1990; Hosag., Meliolales of India, p. 176, 1996.

Materials examined: On leaves, stems and petioles of Cyclea peltata Cooke (Menispermaceae), Meenmutty, Idukki, Kerala, 12.xii.1982, V.B. Hosagoudar HCIO 40516 (type); Castle Rock, Karnataka, 10.i.1984, C.R. Patil HCIO 40014; Peppara, Thiruvananthapuram, Kerala, 5.ii.1997, V.B. Hosagoudar HCIO 43948, TBGT 434; TBGRI campus, Thiruvananthapuram, Kerala, 4.xi.2000, H. Biju, HCIO 44544, TBGT 830; Vettilapara, Vazhachal, Trissur, Kerala, 24.x.2002, H. Biju \& A. Manojkumar TBGT 958.

Colonies amphigenous, mostly epiphyllous, subdense to dense, up to $3 \mathrm{~mm}$ in diameter, confluent. Hyphae substraight to slightly undulate, branching opposite to irregular at acute angles, loosely to closely reticulate, cells $16-28 \times 6-8 \mu \mathrm{m}$. Appressoria alternate to unilateral, straight, antrorse, 20-28 $\mu \mathrm{m}$ long; stalk cells cuneate, $6-12 \mu \mathrm{m}$ long; head cells ovate, versiform, slightly and bluntly pointed at the apex, entire, $14-18 \times 12-14 \mu \mathrm{m}$. Phialides borne on a separate mycelial branch, alternate to opposite, conoid to ampulliform, 14-22 x 6-8 $\mu \mathrm{m}$. Mycelial setae scattered to grouped around the perithecia, simple, acute at the tip, up to $432 \mu \mathrm{m}$ long. Perithecia scattered, verrucose, up to $160 \mu \mathrm{m}$ in diameter; ascospores oblong, 4-septate, slightly constricted, $34-40 \times 16-20 \mu \mathrm{m}$.

Host range: Cyclea peltata

Distribution: India

26. Meliola cymbopogonis Kapoor, Indian Phytopathol. 20: 152, 1967; Hosag. \& Goos, Mycotaxon 37: 229, 1990; Hosag., Meliolales of India, p. 177, 1996.
Materials examined: On leaves of Cymbopogon nardus (L.) Rendle (Poaceae), Wyanad, Kerala, 13.ix.1909, W. McRae HCIO 28213 (type); C. flexuous (Nees ex Steud.) Wats., Vazhathope, Idukki, Kerala, 26.iii.1983, V.B. Hosagoudar MH 75879; Idukki, Kerala, 4.x.1983, V.B. Hosagoudar MH 781521 HCIO 34972.

Colonies epiphyllous, rarely amphigenous, subdense to dense, velvety, up to $3 \mathrm{~mm}$ in diameter. Hyphae straight to tortuous, straight hyphae run along the veins and tortuous hyphae cross the straight hyphae, branching mostly opposite at wide to acute angles, loosely to closely reticulate, cells $14-22$ x $6-8 \mu \mathrm{m}$. Appressoria alternate, unilateral, antrorse, spreading, $10-24 \mu \mathrm{m}$ long; stalk cells cuneate to cylindrical, $4-12 \mu \mathrm{m}$ long; head cells ovate, globose, angular to sublobate, $10-14$ x 12-14 $\mu \mathrm{m}$. Phialides few, mixed with appressoria, opposite to alternate, ampulliform, $12-18$ x 10-12 $\mu \mathrm{m}$. Mycelial setae straight, dichotomously branched at the tip, up to $176 \mu \mathrm{m}$ long till branching, primary branch up to $20 \mu \mathrm{m}$ long, while tertiary up to $10 \mu \mathrm{m}$ long, branchlets reflexed, acute to obtuse at the tip. Perithecia scattered, verrucose, up to $120 \mu \mathrm{m}$ in diameter; ascospores ellipsoidal, 4-septate, constricted, 38-44 x 12-14 $\mu \mathrm{m}$.

Host range: Cymbopogon spp.

Distribution: India

27. Meliola diospyri Sydow \& Sydow in Sydow \& Butler, Ann. Mycol. 9: 281, 1911; Hansf., Sydowia Beih. 2: 498, 1961; Thite \& Kulkarni, J. Shivaji Univ. (Sci.) 6: 162, 1973; Srinivasulu, Nova Hedwigia Beih. 47: 426, 1974; Maity, Indian J. Mycol. Res. 16: 25, 1978; Hosag. \& Goos, Mycotaxon 37: 230, 1990; Hosag., Siddappa \& Udaiyarn, Nova Hedwigia 56: 197, 1993; Hosag., Raghu \& Pillai, Nova Hedwigia 58: 538, 1994; Hosag., Meliolales of India, p. 181, 1996.

Materials examined: On leaves of Diospyros montana Roxb. (Ebenaceae), Koppa, Karnataka, 15.ix.1903, E.J. Butler HCIO 1044; D. nigrescens (Dalzel) Saldhana, Radhanagari, Kolhapur, Maharashtra, 10.xi.1974, M.S. Patil HCIO 31944; D. pruriens Dalz., Petlond, Sangli, Maharashtra, 20.iv.1984, C.R. Patil HCIO 40003; Diospyros sp., Anmode, Maharashtra, x.1974, A.N. Thite HCIO 31905; D. sylvatica Roxb., Calvary Mount, Idukki, Kerala, 5.x.1983, V.B. Hosagoudar HCIO 40520, MH 78169; Anmode, Maharashtra, 17.x.1974, A.N. Thite HCIO 31905; Diospyros sp., in the campus of TBGRI, palode, Thiruvananthapuram, Kerala, 10.iii.1996, V.B. Hosagoudar HCIO 42187, TBGT 58; D. malabarica (Desr.) Kostel., Bekur, Kasargod, Kerala, 13.ix.1992, P. Ram Bhat HCIO 40758; on D. ebenum Koen., in the campus of TBGRI, palode, Thiruvananthapuram, Kerala 18.xii.2001, H. Biju HCIO 44552, TBGT 838; 7.xii.2001, H. Biju HCIO 44466, TBGT 756; 23.i.2001, H. Biju HCIO 44545, TBGT 813.

Colonies amphigenous, mostly hypophyllous, subdense to dense, up to $5 \mathrm{~mm}$ in diameter, confluent. Hyphae straight to slightly undulate, branching opposite at wide to acute angles, loosely reticulate, cells 20-36 x 6-10 $\mu \mathrm{m}$. Appressoria alternate, about $40 \%$ opposite, antrorse, spreading, 18-26 $\mu \mathrm{m}$ long; stalk cells cylindrical to cuneate, $4-8 \mu \mathrm{m}$ long; head cells ovate, versiform, entire, rarely angular, $14-18$ x 8-10 $\mu \mathrm{m}$. Phialides 
numerous, mixed with appressoria, alternate to opposite, ampulliform, 20-28 x 8-10 $\mu \mathrm{m}$. Mycelial setae scattered, straight, simple, acute to obtuse at the tip, up to $774 \mu \mathrm{m}$ long. Perithecia scattered to grouped, up to $200 \mu \mathrm{m}$ in diameter; ascospores obovoidal,4-septate, constricted, $42-50 \times 16-18 \mu \mathrm{m}$.

Host range: Diospyros spp.

Distribution: India

28. Meliola dysoxyli-malabarici Hosag. \& Kamar., Zoos' Print J. 17: 749, 2002.

Materials examined: On leaves of Dysoxylum malabaricum (Meliaceae), Kerala, India, 5.ix.2001, M. Kamarudeen TBGT 565.

Colonies hypophyllous, subdense, up to $2 \mathrm{~mm}$ in diameter, confluent. Hyphae substraight, branching irregular at acute to wide angles, loosely to closely reticulate, cells $22-26$ x 4-5 $\mu \mathrm{m}$. Appressoria alternate, unilateral, about $30 \%$ opposite, antrorse, subantrorse to slightly retrorse, 11-16 $\mu \mathrm{m}$ long; stalk cells cylindrical to cuneate, $2-5 \mu \mathrm{m}$ long; head cells ovate, entire, straight to slightly recurved, broadly rounded at the apex, 8-11 x 6-8 $\mu \mathrm{m}$. Phialides mixed with appressoria, alternate to opposite, ampulliform, $16-18 \times 6-8 \mu \mathrm{m}$. Mycelial setae two type: setae scattered on mycelia are simple, straight, mostly obtuse at the tip, up to $1470 \mu \mathrm{m}$ long; setae grouped around perithecia are simple, straight, curved, uncinate, acute at the tip, up to $150 \mu \mathrm{m}$ long. Perithecia scattered, globose, up to $175 \mu \mathrm{m}$ in diameter; ascospores obovoidal, 4-septate, constricted at the septa, 30$32 \times 12-16 \mu \mathrm{m}$.

Host range: Dysoxylum malabaricum

Distribution: India

29. Meliola entadicola Deighton, Sydowia 11: 104, 1958; Hansf., Sydowia Beih. 2: 260, 1961; Hosag., Kaveriappa, Raghu ;\& Goos, Mycotaxon 51: 111, 1994; Hosag., Meliolales of India, p. $187,1996$.

Materials examined: On leaves of Entada rheedii Sprengel (E. persaetha DC.) (Mimosaceae), Gersoppa, Uttara Kannada, Karnataka, 24.x.1992, P.A. Raghu HCIO 40867.

Colonies amphigenous, mostly epiphyllous, thin, confluent. Hyphae straight to substraight, branching alternate to opposite at acute angles, loosely to closely reticulate, cells 24-34 x 4$6.5 \mu \mathrm{m}$. Appressoria alternate and opposite, straight to curved, antrorse to recurved, $12-15.5 \mu \mathrm{m}$ long; stalk cells cylindrical to cuneate, 4-6.5 $\mu \mathrm{m}$ long; head cells ovoid, globose to oblong, entire to rarely angular, 7-9.5 x 6-8 $\mu \mathrm{m}$. Phialides mixed with appressoria, alternate to opposite, ampulliform, 15-22 x 6-9.5 $\mu \mathrm{m}$. Mycelial setae fairly numerous, scattered, straight to rarely and slightly flexuous at the upper portion, acute, obtuse to dentate at the tip, up to $430 \mu \mathrm{m}$. Perithecia scattered, up to $126 \mu \mathrm{m}$ in diameter; ascospores oblong to cylindrical, 4-septate, slightly constricted at the septa, $34-37.5 \times 12-15.5 \mu \mathrm{m}$.

Host range: Entada rheedii
Distribution: Tropics

30. Meliola floridensis Hansf., Sydowia 10: 72, 1957; Sydowia Beih. 2: 56, 1961; Hosag. \& Goos, Mycotaxon 37: 408, 1990; Hosag., Meliolales of India, p. 199, 1996.

Materials examined: On leaves of Persea macrantha (Nees) Kosterm (Lauraceae), Pudukadu, Lower Sheikalmudi, Coimbatore, Tamil Nadu, 17.i.1987, V.B. Hosagoudar HCIO 39437.

Colonies amphigenous, mostly epiphyllous, subdense, crustose, up to $2 \mathrm{~mm}$ in diameter, rarely confluent. Hyphae straight to slightly undulate, branching alternate to opposite at acute angles, very closely ;reticulate, cells $12-15.5$ x 7-9.5 $\mu \mathrm{m}$. Appressoria alternate, antrorse to subantrorse, straight to slightly curved, $18-28 \mu \mathrm{m}$ long; stalk cells cuneate, $3-12.5 \mu \mathrm{m}$ long; head cells obovate, clavate, globose, entire to rarely angular, $15-18.5 \times 12-15 \mu \mathrm{m}$. Phialides not seen. Mycelial setae scattered to grouped around perithecia, simple, straight, acute to obtuse, up to $430 \mu \mathrm{m}$ long. Perithecia scattered to loosely grouped at the centre, verrucose, up to $170 \mu \mathrm{m}$ in diam.; ascospores cylindrical, 4-septate, strongly constricted, 52-56 x $18-22 \mu \mathrm{m}$.

Host range: Persea macrantha

Distribution: Tropics

32. Meliola gamsii Hosag. \& S. Shiburaj, Nova Hedwigia 74: $411,2002$.

Materials examined: On leaves of Strychnos nux-vomica (Strychnaceae), Kerala, India, 17.ix.1998, S. Shiburaj TBGT 407; Eanikara, Thiruvananthapuram, Kerala, 23.i.2001, V.B. Hosagoudar HCIO 44067, TBGT 505; 26.i.2001, V.B. Hosagoudar HCIO 44133, TBGT 515; Anchal, Kollam, Kerala, 23.ix.2001, M.M. Shajivaj HCIO 44362, TBGT 652.

Colonies mostly epiphyllous rarely amphigenous, dense, up to $2 \mathrm{~mm}$ diam., confluent. Hyphae mostly straight to substraight, branching mostly opposite at acute angles, loosely to closely reticulate, cells $28-35 \times 6-7 \mu \mathrm{m}$. Appressoria alternate, antrorse, straight to slightly curved, 19-24 $\mu \mathrm{m}$ long; stalk cells cylindrical to cuneate, 6-8 $\mu \mathrm{m}$ long; head cells ovate, oblong, attenuated to broadly rounded at the apex, entire, $12-16 \times 8-10 \mu \mathrm{m}$. Phialides mixed with appressoria, alternate to opposite, ampulliform, neck with elongated, $12-28 \times 6-7 \mu \mathrm{m}$. Mycelial setae scattered, simple, straight, partly (about 10\%) curved to arcuate, acute to subacute at the tip, up to $350 \mu \mathrm{m}$ long. Perithecia scattered, verrucose, up to $135 \mu \mathrm{m}$ diam., ascospores oblong to cylindrical, 4-septate, constricted at the septa, 30-40 x 12-15 $\mu \mathrm{m}$.

Host range: Strychnos nux-vomica

Distribution: India

33. Meliola hemidesmi Kamal \& Gupta, Indian J. Mycol. Pl. Pathol. 16: 245, 1986 (hemidesmae); Hosag., Meliolales of India, p. 212, 1996. 
Materials examined: Material was not available for the study.

Type: On leaves of Hemidesmus indicus (L.) R.Br. (Periplocaceae), Gorakhpur, Uttar Pradesh, B.K. Gupta IMI 281887 (type).

Colonies amphigenous, dense. Hyphae sinuous to flexuous, branching opposite at acute to wide angles, loosely reticulate, cells $15-35 \times 4-9 \mu \mathrm{m}$. Appressoria alternate, straight to curved, subantrorse to retrorse, $9-20 \mu \mathrm{m}$ long; stalk cells cylindrical to cuneate, $3-8 \mu \mathrm{m}$ long; head cells ovate, entire, 6-12.5 x 4-6 $\mu \mathrm{m}$. Phialides not seen. Mycelial setae numerous, simple, straight, acute to obtuse at the apex, up to $400 \mu \mathrm{m}$ long. Perithecia scattered, up to $250 \mu \mathrm{m}$ in diam.; ascospores cylindrical, 4septate, slightly constricted at the septa, $25-55 \times 12-18 \mu \mathrm{m}$.

Host range: Hemidesmus indicus

Distribution: Tropics

34. Meliola hemidesmicola Hosag., Meliolales of India, p. 212, 1996.

Materials examined: On leaves of Hemidesmus indicus (L.) R. Br. (Periplocaceae), Panhala, Maharashtra, x.1980, A.N. Thite HCIO 33673 (type); Peppara, Thiruvananthapuram, Kerala, 5.ii.1997, V.B. Hosagoudar HCIO 42512, TBGT 174; Vithura, Thiruvananthapuram, Kerala, 3.xii.2000, M. Kamarudeen HCIO 43824, TBGT 363; TBGRI campus, Palode, Thiruvananthapuram, Kerala, 18.xii.2001, H. Biju HCIO 44576, TBGT 863; in the forest, near Kushvoor, Palode, Thiruvananthapuram, Kerala, 1.ix. 2002, A. Manojkumar HCIO 44593, TBGT 880.

Colonies epiphyllous, dense, confluent and cover the entire upper leaf surface. Hyphae straight to slightly flexuous, branching mostly opposite at wide angles, loosely to closely reticulate, cells $24-28 \times 6-8 \mu \mathrm{m}$. Appressoria alternate, antrorse to subantrorse, $18-22 \mu \mathrm{m}$ long; stalk cells cylindrical to cuneate, 5-7 $\mu \mathrm{m}$ long; head cells ovate, globose, entire, 12-15.5 x 9-12.5 $\mu \mathrm{m}$. Phialides mixed with appressoria, alternate to opposite, ampulliform, 21-25 x 5-7 $\mu \mathrm{m}$. Mycelial setae fairly numerous, scattered, simple, straight, acute at the tip, up to $650 \mu \mathrm{m}$ long. Perithecia scattered, verrucose, up to $124 \mu \mathrm{m}$ in diam.; ascospores oblong to subellipsoidal, 4-septate, constricted at the septa, $32-35 \times 12-15.5 \mu \mathrm{m}$.

Host range: Hemidesmus indicus

Distribution: India

35. Meliola hydnocarpi Hansf. var. indica Hosag. \& Kamar., Zoos' Print J. 17: 750, 2002.

Materials examined: On leaves of Hydnocarpus pentandra (Flacourtiaceae), Kerala, India, 6.ix.2001, M. Kamarudeen HCIO. TBGT 564; H. laurifolius (Dennst.) Sleumer, Parakuzhy forest area, Karikulam, Ranni, Pathanamthitta, Kerala, 4.x.2002, A. Manojkumar TBGT 941.

Colonies hypophyllous, dense, velvety, up to $3 \mathrm{~mm}$ in diameter, rarely confluent. Hyphae substraight to crooked, branching irregular at acute to wide angles, loosely to closely reticulate, cells $25-35 \times 6-7 \mu \mathrm{m}$. Appressoria alternate, about $2 \%$ opposite, antrorse to subantrorse, straight to curved, 14-18 $\mu \mathrm{m}$ long; stalk cells cylindrical to cuneate, $4-6.5 \mu \mathrm{m}$ long; head cells ovate to globose, straight to curved, entire to rarely angular, 9-11 x 7$9 \mu \mathrm{m}$. Mycelial setae densely scattered on the colonies, simple, straight, rarely about $1 \%$ uncinate, acute at the tip, up to $350 \mu \mathrm{m}$ long. Perithecia scattered, globose, up to $163 \mu \mathrm{m}$ in diameter; ascospores oblong to cylindrical, 4-septate, constricted at the septa, $36-40 \times 12-15 \mu \mathrm{m}$.

Host range: Hydnocarpus spp.

Distribution: India

36. Meliola ichnocarpi-volubili Hansf., Sydowia 16: 320, 1963. Meliola ichnocarpi Stev. \& Rold., Philippine J. Sci. 56: 66, 1935 (non Hansf. \& Thirum., 1948); Hansf., Sydowia Beih. 2: 561, 1961.

Materials examined: On leaves of Ichnocarpus frutescense (L.) R. Br. (Apocynaceae), in the campus of Tropical Botanic Garden and Research Institute, Palode, Thiruvananthapuram, Kerala, 5.ix.2002, H. Biju HCIO 44637, TBGT 919.

Colonies mostly epiphyllous, subdense, up to $5 \mathrm{~mm}$ in diameter. Hyphae straight to flexuous, branching mostly opposite at acute angles, loosely reticulate, cells 19-24 x 4-6 $\mu \mathrm{m}$. Appressoria alternate, antrorse to closely antrorse, $12-18 \mu \mathrm{m}$ long; stalk cells cylindrical to cuneate, $3-7 \mu \mathrm{m}$ long; head cells ovate, globose, slightly attenuated to truncate at the apex, mostly entire, rarely

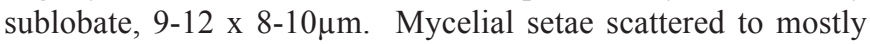
grouped around perithecia, simple, straight, curved, acute to obtuse at the apex, up to $600 \mu \mathrm{m}$ long. Perithecia scattered, globose, often peridial cells projected, up to $125 \mu \mathrm{m}$ in diameter; ascospores oblong to slightly ellipsoidal, 4-septate, slightly constricted, $35-37 \times 11-13 \mu \mathrm{m}$.

Host range: Ichnocarpus frutescense

Distribution: Asia

37. Meliola kingiodendri Hosag., Dayal \& Goos, Mycotaxon 46: 205, 1993; Hosag., Meliolales of India, p. 234, 1996.

Materials examined: On leaves of Kingiodendron pinnatum (Roxb.) Harms (Caesalpiniaceae), Sampaje forest nursery, Sampaje, Kodagu, Karnataka, B.R. Dayal HCIO 30836 (type).

Colonies hypophyllous, rarely amphigenous, dense, up to 5 $\mathrm{mm}$ in diameter, rarely confluent. Hyphae straight, very rarely crooked, branching mostly opposite at acute to wide angles, loosely reticulate, cells 27-35.5 x 6-9.5 $\mu \mathrm{m}$. Appressoria opposite, rarely solitary, antrorse to recurved to spreading, $15-18 \mu \mathrm{m}$ long; stalk cells cylindrical to cuneate, $3-6.5 \mu \mathrm{m}$ long; head cells pyriform, conoid with rounded ends, straight, curved to recurved, entire, $12-15.5 \times 6-9.5 \mu \mathrm{m}$. Phialides mixed with appressoria, alternate to opposite, ampulliform, straight to curved at the apex, $18-25 \times 9-12 \mu \mathrm{m}$. Mycelial setae evenly scattered on the colonies, simple, straight, obtuse to dentate at 
the tip, up to $575 \mu \mathrm{m}$ long. Perithecia scattered, globose, up to $248 \mu \mathrm{m}$ in diam.; perithecial cells projected, rounded at the apex; ascospores ellipsoidal, 4-septate, constricted at the septa, 37$40.5 \times 18-22 \mu \mathrm{m}$.

Host range: Kingiodendron pinnatum

Distribution: India

38. Meliola kydiae-calycinae Hansf. \& Thirum., Farlowia 3: 296, 1948; Hansf., Sydowia Beih. 2: 188, 1961; Hosag., Meliolales of India, p. 235, 1996.

Materials examined: Material was not available for the present study and the report is on Kydia calycina Roxb., Karnataka, Thirumalachar No. 852.

Colonies mostly epiphyllous, dense, velvety, up to $4 \mathrm{~mm}$ in diameter, confluent. Hyphae undulate to crooked, branching opposite to irregular at wide angles, closely reticulate, cells 20$30 \times 7-9 \mu \mathrm{m}$. Appressoria alternate, antrorse to spreading, 15$24 \mu \mathrm{m}$ long; stalk cells cylindrical to cuneate, $4-10 \mu \mathrm{m}$ long; head cells angulose to irregularly sublobate, straight to curved, 10$15 \times 12-19 \mu \mathrm{m}$. Phialides borne on a separate mycelial branch, opposite to alternate, conoid to ampulliform, 16-23 x 6-8 $\mu \mathrm{m}$. Mycelial setae numerous, mostly grouped around perithecia, straight to curved, simple, acute to obtuse, up to $340 \mu \mathrm{m}$ long. Perithecia scattered, verrucose, up to $180 \mu \mathrm{m}$ in diam.; ascospores ellipsoidal to cylindrical, 4-septate, constricted, 33-39 x 10-12 $\mu \mathrm{m}$.

Host range: Kydia calycina

Distribution: India

39. Meliola machili Yamam., Trans. Nat. Hist. Soc. Taiwan 31 : 23, 1941; Hansf., Sydowia Beih. 2: 54, 1961; Hosag. \& Goos, Mycotaxon 37: 239, 1990; Hosag., Dayal \& Goos, Mycotaxon 46: 206, 1993; Hosag., Meliolales of India, p. 244, 1996.

Materials examined: On leaves of Persea macrantha (Nees) Kosteerm. (Machilus macrantha Nees) (Lauraceae), Idukki, Kerala, 12.i.1982, V.B. Hosagoudar HCIO 40543, MH 72681; 19.iv.1982, V.B. Hosagoudar MH 73646, 73711; 15.xii.1982, V.B. Hosagoudar MH 75764; Lakshmi Estate, Idukki, Kerala, 12.vi.1983, V.B. Hosagoudar MH 75091, 75092, 75094; Pooyankutty, Kerala, 16.vi.1983, V.B. Hosagoudar MH 79021; Idukki, Kerala, 3.x.1983, V.B. Hosagoudar MH 78134; 28.xii.1983, V.B.Hosagoudar MH 80320; Calvary Mount, Idukki, Kerala, 24.ii.1984, M. Ali MH 80371; Idukki, Kerala, 25.x.1984, A. Diraviadoss MH 82612; Pudukadu, Lower Sheikalmudy, Coimbatore, Tamil Nadu, 17.i.1987, V.B. Hosagoudar MH 82670 , 82678, 82684; Sampaje forest nursery, Sampaje, Kodagu, Karnataka, 22.xii.1991, B.R.Dayal HCIO 30834; Peppara, Thiruvananthapuram, 5.ii.1997, V.B. Hosagoudar HCIO 42510, TBGT 176; Kombe, Thiruvananthapuram, Kerala, 20.ii.1997, Meenmutty, Thiruvananthapuram, Kerala, 9.iii.1996, V.B. Hosagoudar HCIO 42165, TBGT 27.

Colonies hypophyllous, dense, velvety, up to $6 \mathrm{~mm}$ in diameter, confluent. Hyphae crooked and geniculate, branching opposite to irregular at acute to wide angles, closely reticulate, rarely form solid mycelial mat, cells 20-28 x 6-10 $\mu$ m. Appressoria alternate to unilateral, straight to curved, antrorse, spreading, $16-22 \mu \mathrm{m}$ long; stalk cells cylindrical to cuneate, $4-10 \mu \mathrm{m}$ long; head cells ovate, globose, slightly angular, truncate, entire, 12$14 \times 14-16 \mu \mathrm{m}$. Phialides mixed with appressoria, alternate to unilateral, 10-16 x 8-12 $\mu \mathrm{m}$. Mycelial setae numerous, scattered to grouped around perithecia, straight, simple, acute at the tip, up to $486 \mu \mathrm{m}$ long. Perithecia scattered, verrucose, up to $246 \mu \mathrm{m}$ in diam.; ascospores obovoidal to cylindrical, 4-septate, constricted, $54-56 \times 18-22 \mu \mathrm{m}$.

Host range: Persea macrantha

Distribution: Tropics

40. Meliola melanoxylonis Hosag. \& Pillai in Hosag., Raghu \& Pillai, Nova Hedwigia 58:540, 1994; Hosag., Meliolales of India, p. 255, 1996.

Materials examined: On leaves of Acacia melanoxylon R. Br. (Mimosaceae), Vettiyar, Mavelikara, Kerala, 14.ix.1992, C.M. Pillai HCIO 40763; Ponmudy hills, Thiruvananthapuram, Kerala, 10.x.2000, C.K. Biju HCIO 44016, TBGT 438; Ramagirikotta, Palghat, Kerala, vii.2002, A. Manojkumar \& H. Biju HCIO 44524, TBGT 810; TBGRI campus, Palode, Thiruvananthapuram, Kerala, 23.i.2001, H. Biju HCIO 44543, TBGT 829; Hyderabad, Andhra Pradesh, 16.vi.2002, G. Bagyanarayana HCIO 44601, TBGT 888; Vandanam, Alapuzha, Kerala, 3.x.2002, A. Manojkumar TBGT 956; Pariyaram forest range office, Chalakudy, Trissur, Kerala, 22.x.2002, A. Manojkumar TBGT 963; A. sinuata (Lour.) Merr., Sampaje forest nursery, Sampaje, Kodagu, Karnataka, 22.xii.1991, B.R. Dayal HCIO 30832; on the way to Alapuzha, Kerala, 21.x.2002, A. Manojkumar TBGT 967; Acacia sp., KFRI campus, Peechi, Trissur, Kerala, 5.vi.1997, K.V. Sankaran TBGT 142; Chettikulam, Chalakudy, Trissur, Kerala, 22.x.2002, H. Biju \& A. Manojkumar TBGT 986; Peelarmuzhy, Trissur, Kerala, 22.x.2002, H. Biju \& A. Manojkumar TBGT 965; Kamarudeen HCIO 43955, TBGT 437; Peppara, Thiruvananthapuram, Kerala, 6.ii.1997, V.B. Hosagoudar HCIO 43953, TBGT 439;

Colonies amphigenous, mostly epiphyllous, scattered, dense, subvelvety, up to $2 \mathrm{~mm}$ in diameter. Hyphae substraight to crooked, branching alternate, opposite to irregular at wide angles, loosely to closely reticulate, cells $15-22$ × 3-5 $\mu \mathrm{m}$. Appressoria mostly opposite, rarely alternate to solitary, straight to curved, antrorse, subantrorse to recurved, 12-18.5 $\mu \mathrm{m}$ long; stalk cells cylindrical to cuneate, $3-6.5 \mu \mathrm{m}$ long; head cells globose, ovate, cyli ndrical, entire to angular, 9-12.5 x 6-9.5 $\mu \mathrm{m}$. Phialides mixed with appressoria, alternate to opposite, 12-15.5 x 6-8 $\mu \mathrm{m}$. Mycelial setae numerous,; scattered, simple, straight, obtuse to 2-3 dentate at the tip, up to $650 \mu \mathrm{m}$ long. Perithecia sscattered, verrucose, up to $124 \mu \mathrm{m}$ in diam.; ascospores obovoidal, 4-septate, constricted, 34-37.5 x 14-16 $\mu \mathrm{m}$.

Host range: Acacia spp.

Distribution: India 
41. Meliola mucunae-acuminatae Hansf. var. indica Hosag., Siddappa \& Udaiyan, Nova Hedwigia 56: 198, 1993; Hosag., Meliolales of India, p. 261, 1996.

Materials examined: On leaves of Mucuna pruriens (L.) DC. (Fabaceae), Anmode, Maharashtra, 10.x.1994, A.N. Thite HCIO 31907 (type).

Colonies epiphyllous, thin to dense, confluent. Hyphae crooked, branching opposite to irregular at wide angles, loosely reticulate, cells $15-28 \times 4-6.5 \mu \mathrm{m}$. Appressoria alternate, about $5 \%$ opposite, straight to variously curved, $12-18.5 \mu \mathrm{m}$ long; stalk cells cylindrical to cuneate, $3-6.5 \mu \mathrm{m}$ long; head cells ovate, globose, entire, curved, 9-12.5 x 10-12.5 $\mu \mathrm{m}$. Phialides mixed with appressoria, alternate to opposite, conoid to ampulliform, 18.5-25 x 6-8 $\mu \mathrm{m}$. Mycelial setae few, grouped around perithecia, simple, straight, acute, obtuse to few dentate at the tip, up to $280 \mu \mathrm{m}$ long. Perithecia scattered, up to $125 \mu \mathrm{m}$ in diam.; ascospores cylindrical, 4-septate, constricted at the septa, 3034 x $12-15.5 \mu \mathrm{m}$.

Host range: Mucuna pruriens

Distribution: India

42. Meliola panici Earle var. vetiveriicola Hosag.\& Shajivaz (in press)

Materials examined: On leaves of Vetiveria zizanoides (L.) Nash (Poaceae), Medicinal plants garden, Tropical Botanic Garden and Research Institute, Palode, Thiruvananthapuram, Kerala, India, 29.xi.2001, M.M. Shajivaz. HCIO 44577, TBGT 864

Colonies amphigenous, mostly epiphyllous, dense, crustose, up to $2 \mathrm{~mm}$ in diameter, confluent. Hyphae substraight to flexuous, branching irregular at acute angles, loosely to closely reticulate, cells 19-24 x 6-8 $\mu \mathrm{m}$. Appressoria alternate to unilateral, antrorse to subantrorse, $20-24 \mu \mathrm{m}$ long; stalk cells cylindrical to cuneate, $8-10 \mu \mathrm{m}$ long; head cells ovate, globose, entire, angular, lobate to stellately lobate, $13-15 \times 11-16 \mu \mathrm{m}$. Phialides borne on a separate mycelial branch, alternate, opposite to unilateral, ampulliform, 16-20 x 6-8 $\mu \mathrm{m}$. Mycelial setae scattered to grouped around perithecia, simple, straight, curved to rarely uncinate, acute to obtuse at the tip, up to $400 \mu \mathrm{m}$ long. Perithecia loosely grouped, globose, up to $125 \mu \mathrm{m}$ in diameter; ascospores oblong, 4-septate, slightly constricted at the septa, 33-39 x 12-16 $\mu \mathrm{m}$.

Host range: Vetiveria zizanoides

Distribution: India

43. Meliola petchii Hansf., Proc. Linn. Soc. London 157: 182, 1946; Sydowia Beih. 2: 527, 1961; Hosag., Lakshmanan \& Viswanathan, Indian J. Bot. 11: 187, 1988; Hosag., Raghu \& Pillai, Nova Hedwigia 58: 542, 1994; Hosag., Meliolales of India, p. 281, 1996.

Materials examined: On leaves of Strychnos nux-vomica L. (Loganiaceae), Malabar, Kerala, 17.xi.1912, T.R. Ranganath HCIO 10488; Taliparamba, Kerala, 27.v.1952, N.V. Sundaram HCIO
20422 (as M. stenospora); Londha, Karnataka, xii.1971, A.N. Thite HCIO 31908; Calicut, Kerala, 17.xi.1986, V.B. Hosagoudar AMH 7135; Gersoppa, uttara Kannada, Karnataka, 23.ix.1992, P.A. Raghu HCIO 40765.

Colonies epiphyllous, rarely hypophyllous, dense, thinly velvety, up to $4 \mathrm{~mm}$ in diameter, largely confluent. Hyphae straight, branching opposite at acute angles, loosely reticulate, cells $18-28 \times 4-6 \mu \mathrm{m}$. Appressoria alternate, straight, antrorse, 18-25 $\mu \mathrm{m}$ long; stalk cells cuneate, 6-9.5 $\mu \mathrm{m}$ long; head cells ovate, broadly rounded at the apex, entire $12-15.5 \times 9-11 \mu \mathrm{m}$. Phialides mixed with appressoria, opposite to alternate, ampulliform, 12$15.5 \times 6-9.5 \mu \mathrm{m}$. Mycelial setae few, mostly grouped around perithecia, simple, straight, acute to obtuse, up to $232 \mu \mathrm{m}$ long. Perithecia scattered, verrucose, up to $124 \mu \mathrm{m}$ in diam.; ascospores obovoidal, 4-septate, slightly constricted, 31-35.5 x 12-15.5 $\mu \mathrm{m}$.

Host range: Strychnos nux-vomica

Distribution: India

44. Meliola pongamiae Hosag. \& Abraham, Nova Hedwigia 68: 483, 1998.

Materials examined: On leaves of Pongamia pinnata (Fabaceae), TBGRI campus, Thiruvananthapuram, Kerala, India, 21.i.1997, V.B. Hosagoudar TBGT 123, HCIO 42482; 20.xi.2000, V.B. Hosagoudar HCIO 42482, TBGT 123; 18.xii.2000, H. Biju HCIO 44542, TBGT 828; 23.i.2001, H. Biju HCIO 44563, TBGT 850; 20.xi.2000, V.B. Hosagoudar HCIO 43950, TBGT 422; Peringammala, Thiruvan-anthapuram, Kerala, 25.ix.2000, M. Kamarudeen HCIO 43965, TBGT443.

Colonies epiphyllous, crustose, up to $5 \mathrm{~mm}$ in diameter. Surrounded by yellow haloes, with yellow discolouration of the lower leaf surface, several such spots causing defoliation. Hyphae straight to substraight, branching mostly opposite at wide angles, loosely to closely reticulate, cells $17-29 \times 4-8 \mu \mathrm{m}$. Appressoria alternate, about $2 \%$ opposite, antrorse, subantrorse to retrorse, $14-22 \mu \mathrm{m}$ long; stalk cells cylindrical to cuneate, $2-7 \mu \mathrm{m}$ long; head cells ovate, globose, $12-15$ x 9-12 $\mu \mathrm{m}$. Phialides mixed with appressoria, alternate to opposite, ampulliform, neck twisted, 19-22 x 7-10 $\mu \mathrm{m}$. Mycelial setae scattered, simple, straight, acute at the tip, up to $255 \mu \mathrm{m}$ long. Perithecia scattered loosely to grouped, verrucose, up to $150 \mu \mathrm{m}$ in diameter; ascospores oblong to cylindrical, 4-septate, slightly constricted, 38-44 x 14-17 $\mu \mathrm{m}$.

Host range: Pongamia pinnata

Distribution: India

45. Meliola pterocarpi Yates, Philippine J. Sci. 13: 235, 1918; Hansf., Sydowia Beih. 2: 299, 1961; Hosag., Dayal \& Goos, Mycotaxon 46: 208, 1993; Hosag., Meliolales of India, p. 290, 1996.

Materials examined: On leaves of Pterocarpus marsupium Roxb. (Fabaceae), Sampaje forest nursery, Sampaje, Kodagu, Karnataka, 22.xii.1991, B.R. Dayal HCIO 30835; Peppara, 
Thiruvanantha-puram, Kerala, 3.ii.1997, V.B. Hosagoudar HCIO 42494, TBGT 144; 6.ii.1997, V.B. Hosagoudar HCIO 43951, TBGT 445; Kombe, Peppara and Neyyar Wildlife Sancturies, Thiruvananthapuram, Kerala, 19.ii.1997, V.B. Hosagoudar TBGT 196; 8.iii.2001, H. Biju HCIO 44453, TBGT 742; on Pterocarpus santalinus L.f., in the campus of TBGRI, Palode, Thiruvananthapuram, Kerala, 18.xii.2001, H. Biju HCIO 44492, TBGT 782.

Colonies amphigenous, mostly epiphyllous, dense, up to $3 \mathrm{~mm}$ in diam., rarely confluent. Hyphae substraight to flexuous, branching opposite at acute angles, loosely to closely reticulate, cells $18-31$ x 6-9.5 $\mu \mathrm{m}$. Appressoria alternate, straight to curved, antrorse to reflexed, $15-18 \mu \mathrm{m}$ long; stalk cells cylindrical to cuneate, $6-9.5 \mu \mathrm{m}$; head cells globose to obovoidal, entire to rarely slightly angulose, $12-16 \times 12-15.5 \mu \mathrm{m}$. Phialides mixed with appressoria, alternate to opposite, ampulliform, 15-22 x 7$9.5 \mu \mathrm{m}$. Mycelial setae mostly grouped around perithecia, simple, straight, obtuse at the apex, up to $500 \mu \mathrm{m}$ long. Perithecia scattered, globose, up to $168 \mu \mathrm{m}$ in diam.; ascospores obovoidal, 4-septate, slightly constricted at the septa, 40-43.5 x 15-18.5 $\mu \mathrm{m}$.

Host range: Pterocarpus spp.

Distribution: Asia

46. Meliola ramacharii Hosag., Kavaka 15: 5, 1987; Hosag., Meliolales of India, p. 295, 1996.

Materials examined: On leaves of Persea macrantha (Nees) Kosterm. (Lauraceae), 17.iv.1987, Pudukadu, Valparai, Coimbatore, Tamil Nadu, V.B. Hosagoudar HCIO 39316 (type).

Colonies epiphyllous, each on black leaf spots, subdense to dense, up to $2 \mathrm{~mm}$ in diameter. Hyphae straight to substraight, branching mostly opposite at wide angles, loosely reticulate, cells 21.5-28 x 9-12.5 $\mu \mathrm{m}$. Appressoria alternate, mostly antrorse, rarely spreading, straight to curved, $18.5-25 \mu \mathrm{m}$ long; stalk cells cylindrical to cuneate, $3-6.5 \mu \mathrm{m}$ long; head cells ovate, versiform to cylindrical, entire, straight to slightly curved, 15.5-18.5 x 12.5$15.5 \mu \mathrm{m}$. Phialides mixed with appressoria, opposite to alternate, ampulliform, 15.5-31 x 7.5-9.5 $\mu \mathrm{m}$. Mycelial setae few, grouped around perithecia, straight, simple, acute to obtuse, up to $500 \mu \mathrm{m}$. Perithecia scattered, verrucose, up to $130 \mu \mathrm{m}$ in diam.; ascospores obovoidal, 4-septate, slightly constricted, 37-40.5 x 15.5-18.5 $\mu \mathrm{m}$.

Host range: Persea macrantha

Distribution: India

47. Meliola rauvolfiae Mibey in Mibey \& Hawksworth, Mycol. Pap. 174: 69, 1997.

Materials examined: On leaves of Rauvolfia hookeri Srinivasan \& Chithra (Apocynaceae), Gravel bank, Munnar, Idukki, Kerala, x.2001, S. Shiburaj HCIO 44383, TBGT 628.

Colonies epiphyllous, thin to subdense, up to $3 \mathrm{~mm}$ in diameter, rarely confluent. Hyphae straight to flexuous, branching opposite at acute angles, loosely reticulate, cells $24-40$ x 4-6 $\mu \mathrm{m}$.
Appressoria alternate, antrorse, $12-18 \mu \mathrm{m}$ long; stalk cells cylindrical to cuneate, $3-7 \mu \mathrm{m}$ long; head cells ovate, globose, entire, often attenuated and broadly rounded at the apex, 9-11 x 9-10 $\mu \mathrm{m}$. Phialides mixed with appressoria, alternate to opposite, ampulliform, 12-16 × 6-7 $\mu \mathrm{m}$. Mycelial setae mostly grouped around perithecia, simple, straight to slightly curved, obtuse at the tip, up to $350 \mu \mathrm{m}$ long. Perithecia scattered to mostly grouped, globose, up to $120 \mu \mathrm{m}$ in diam.; ascospores oblong to cylindrical, 4-septate, constricted, 27-32 x 11-15 $\mu \mathrm{m}$.

\section{Host range: Rauvolfia hookeri}

Distribution: Tropics

48. Meliola samaderae Hosag., Ponnuswamy \& C.K. Biju, Indian Phytopathol. 56: 295, 2003.

Materials examined: On leaves of Samadera indica Gaertn. (= Quassia indica (Gaertn.) Nooteboon) (Simaroubaceae), Tropical Botanic Garden and Research Institute, Palode, Thiruvananthapuram, Kerala, India, 18.v.1998, C.K. Biju HCIO 43364, TBGT 263; 5.i.2001, H. Biju HCIO 44511, TBGT 797; 20.i.2001, S. Shiburaj HCIO 44055, TBGT 507.

Colonies amphigenous, predominantly epiphyllous, dense, up to $3 \mathrm{~mm}$ in diameter, confluent. Hyphae straight, branching opposite at acute angles, loosely to closely reticulate, cells 19$24 \times 6-8 \mu \mathrm{m}$. Appressoria alternate, about $2 \%$ opposite, antrorse, mostly straight, rarely curved, $20-25 \mu \mathrm{m}$ long; stalk cells cylindrical to cuneate, 6-8 $\mu \mathrm{m}$ long; head cells ovate, oblong to cylindrical, entire, rarely angular, $14-19 \times 9-11 \mu \mathrm{m}$. Phialides mixed with appressoria, alternate to opposite, conoid to ampulliform, $19-22 \times 8-10 \mu \mathrm{m}$. Mycelial setae thinly to densely scattered, simple, straight, acute, broadly rounded to 1-5 times dentate to once furcate and dentate at the apex, up to $445 \mu \mathrm{m}$ long. Perithecia scattered, verrucose, up to $220 \mu \mathrm{m}$ in diameter; ascospores oblong to ellipsoidal, 4-septate, constricted at the septa, often the central cell slightly larger, 61-63 x 17-19 $\mu \mathrm{m}$.

Host range: Samadera indica

Distribution: India

49. Meliola sarcostigmaticola Hosag., Abraham \& C.K. Biju, Nova Hedwigia 68: 484, 1998.

Materials examined: On leaves of Sarcostigma kleini Wight \& Arn. (Icacinaceae), Kerala, India, 18.iii.1997, V.B. Hosagoudar TBGT 124, HCIO 42483.

Colonies mostly hypophyllous, dense, velvety, up to $3 \mathrm{~mm}$ in diameter, rarely confluent. Hyphae straight to flexuous, branching mostly opposite to irregular at wide angles, loosely to closely reticulate, cells $19-24$ × 6-8 $\mu \mathrm{m}$. Appressoria alternate, subantrorse, straight to rarely curved, $16-23 \mu \mathrm{m}$ long; stalk cells cylindrical to cuneate, $3-7 \mu \mathrm{m}$ long; head cells ovate to cylindrical, straight to rarely curved, entire, 11-15 x 9-11 $\mu \mathrm{m}$. Phialides mixed with appressoria, alternate to opposite, ampulliform, 11-19 x 8-10 $\mu \mathrm{m}$. Mycelial setae scattered, simple, straight to curved but not uncinate, acute, obtuse to variously 
dentate at the tip, up to $490 \mu \mathrm{m}$ long. Perithecia loosely grouped, verrucose, up to $150 \mu \mathrm{m}$ in diameter; ascospores cylindrical, 4septate, slightly constricted, $33-35 \times 12-15 \mu \mathrm{m}$.

Host range: Sarcostigma kleinii

Distribution: India

50. Meliola sarcostigmatis Hosag. in Hosag. \& Goos, Mycotaxon 37: 246, 1990 (Sarcostigmae); Hosag., Meliolales of India, p. 305, 1996.

Materials examined: On leaves of Sarcostigma kleinii Wight \& Arn. (Icacinaceae), Idukki, Kerala, 18.ii.1983, V.B. Hosagoudar HCIO 40561 (type), MH 75835 (isotype).

Colonies hypophyllous, dense, velvety, up to $5 \mathrm{~mm}$ in diameter, rarely confluent. Hyphae substraight to undulate, branching mostly opposite at wide angles, closely reticulate, cells $24-32 \mathrm{x}$ $6-10 \mu \mathrm{m}$. Appressoria alternate, about $10 \%$ opposite, straight to curved, antrorse, spreading, $14-24 \mu \mathrm{m}$ long; stalk cells cylindrical to cuneate, $4-10 \mu \mathrm{m}$ long; head cells ovate, globose, entire, $10-14$ x 8-10 $\mu \mathrm{m}$. Phialides mixed with appressoria, opposite to alternate, ampulliform, 22-26 x 6-10 $\mu \mathrm{m}$. Mycelial setae numerous, scattered, straight, simple, acute to obtuse at the tip, up to $468 \mu \mathrm{m}$ long. Perithecia scattered, surface cells projecting, up to $170 \mu \mathrm{m}$ in diam.; ascospores obovoid, 4-septate, constricted, 38-44 x 14-16 $\mu \mathrm{m}$.

Host range: Sarcostigma kleinii

Distribution: India

51. Meliola semecarpi-anacardii Hosag., Kaveriappa, Raghu \& Goos, Mycotaxon 51: 114, 1994; Hosag., Meliolales of India, p. 308, 1996.

Materials examined: On leaves of Semecarpus anacardium L.f. (Anacardiaceae), Dakhina Kannada, Mangalore, Karnataka, 24.xi.1992, P.A. Raghu HCIO 40877 (type); Peppara, Thiruvananthapuram, Kerala, 5.ii.1997, V.B. Hosagoudar HCIO 42495, TBGT 145.

Colonies epiphyllous, dense, crustose, up to $3 \mathrm{~mm}$ in diameter. Hyphae straight, branching opposite at acute to wide angles, closely reticulate and form dense mycelial mat, cells $15-18.5$ x 6$9.5 \mu \mathrm{m}$. Appressoria alternate, antrorse to subantrorse, $18-28 \mu \mathrm{m}$ long; stalk cells cylindrical to cuneate, 6-9.5 $\mu \mathrm{m}$ long; head cells ovoid to globose, entire to angular, 12.5-18.5 x 12-15.5 $\mu \mathrm{m}$. Phialides mixed with appressoria, alternate to opposite, ampulliform, 18-22 x 9-12.5 $\mu \mathrm{m}$. Mycelial setae numerous, simple, straight, acute at the tip, up to $500 \mu \mathrm{m}$ long. Perithecia scattered to loosely grouped, verrucose, up to $250 \mu \mathrm{m}$ in diam.; ascospores obovoidal, 4-septate, deeply constricted at the septa, 49-56 x $21-25 \mu \mathrm{m}$.

Host range: Semecarpus anacardium

Distribution: India
52. Meliola spigeliae Hansf., Slydowia 9: 49, 1955; Sydowia Beih. 2: 527, 1961; Hosag., Siddappa \& Udaiyan, Nova Hedwigia 56: 200, 1993; Hosag., Meliolales of India, p. 312, 1996.

Materials examined: On leaves of Strychnos nux-vomica L. (Loganiaceae), Londa, Karnataka, xii.1971, A.N. Thite HCIO 31908; Cheppad, Alapuzha, Kerala, 23.xi.2000, M. Kamarudeen HCIO 43822, TBGT 365; in the campus of TBGRI, Palode, Kerala, 23.i.2001, H. Biju HCIO 44535, TBGT 821; 18.i.2001, H. Biju HCIO 44573, TBGT 860.

Colonies amphigenous, subdense to dense, up to $2 \mathrm{~mm}$ in diameter, confluent. Hyphae straight to undulate, branching opposite at acute to wide angles, loosely to closely reticulate, cells $18-37$ x 5-7 $\mu \mathrm{m}$. Appressoria alternate, antrorse, $18-22 \mu \mathrm{m}$ long; stalk cells cuneate, 6-9.5 $\mu \mathrm{m}$ long; head cells ovate, versiform, entire, attenuated and rounded to truncate at the apex, entire, $12-15.5 \times 9-12.5 \mu \mathrm{m}$. Phialides mixed with appressoria, alternate to opposite, ampulliform, $18-25$ x 3-6.5 $\mu \mathrm{m}$. Mycelial setae fairly numerous, scattered, simple, straight, acute to obtuse at the apex, up to $250 \mu \mathrm{m}$ long. Perithecia scattered, up to $155 \mu \mathrm{m}$ in diam.; ascospores obovoidal to cylindrical, 4-septate, constricted at the septa, 31-34 x 12-15.5 $\mu \mathrm{m}$.

Host range: Strychnos nux-vomica

Distribution: India

53. Meliola stenospora Wint., Hedwigia 25: 97, 1886; Hansf., Sydowia Beih. 2: 75, 1961; Hosag. \& Raghu, New Botanist 20: 72, 1993; Hosag., Meliolales of India, p. 314, 1996.

Materials examined: On leaves of Piper sp. (Piperaceae), Gersoppa, Uttar Kannada, Karnataka, 20.x.1992, P.A. Raghu HCIO 40888; P. trichostachyon (Miq.) DC., Petland, Sangli, Maharashtra, 20.iii.1984, C.R. Patil HCIO 40005.

Colonies amphigenous, mostly hypophyllous, thin, spreading, up to $5 \mathrm{~mm}$ in diameter. Hyphae substraight to flexuous, branching opposite to irregular at acute to wide angles, loosely to closely reticulate, cells $18-25$ x 6-9.5 $\mu \mathrm{m}$. Appressoria alternate, antrorse to spreading, $15-25 \mu \mathrm{m}$ long; stalk cells cylindrical to cuneate, 6-9.5 $\mu \mathrm{m}$ long; head cells ovate to globose, angular to very slightly lobate, $9-16 \times 9-15 \mu \mathrm{m}$. Phialides borne on a separate mycelial branch, alternate to opposite, ampulliform, 15-18.5 x 6$9.5 \mu \mathrm{m}$. Mycelial setae scattered to grouped around perithecia, simple, straight, acute to obtuse at the tip, up to $530 \mu \mathrm{m}$ long. Perithecia scattered, verrucose, up to $150 \mu \mathrm{m}$ in diam.; ascospores oblong, 4-septate, constricted at the septa, 40-46.5 x 12-18.5 $\mu \mathrm{m}$.

Host range: Piper spp.

Distribution: Tropics

54. Meliola stenospora Wint. var. major Hansf., Sydowia 16: 303, 1963; Patil \& Pawar, Indian Phytopathol. 39: 306, 1986; Hosag., Meliolales of India, p. 316, 1996.

Meliola stenospora Wint. var. major Hansf., Sydowia Beih. 2: 75, 1961. 
Materials examined: On leaves of Piper nigrum L. (Piperaceae), Mahabaleshwar, Satara, Maharashtra, 22.iii.1980, M.S. Patil HCIO 36749; Veerapuli Reserve Forest, Kanniyakumari, Tamil Nadu, 25.ii.1994, V.B. Hosagoudar HCIO 41610.

Colonies mostly epiphyllous, subdense, thinly velvety, up to $3 \mathrm{~mm}$ in diameter, confluent. Hyphae substraight to slightly undulate, branching opposite to irregular at wide angles, closely reticulate, cells 20-25 x 8-10 $\mu \mathrm{m}$. Appressoria alternate, about $1 \%$ opposite, spreading to antrorse, straight to curved, $17-23 \mu \mathrm{m}$ long; stalk cells cuneate to cylindrical, 3-9 $\mu \mathrm{m}$ long; head cells subglobose with crenate to lobulate margin, 11-15 x 12-20 $\mu \mathrm{m}$. Phialides borne on a separate mycelial branch, opposite to alternate, ampulliform, 17-20 x 7-9 $\mu \mathrm{m}$. Mycelial setae mostly grouped around perithecia, straight, simple, acute, up to $1000 \mu \mathrm{m}$ long. Perithecia loosely grouped, verrucose, up to $170 \mu \mathrm{m}$ in diam.; ascospores oblong, 4-septate, slightly constricted, 37$43 \times 11-15 \mu \mathrm{m}$.

Host range: Piper nigrum

Distribution: Asia

55. Meliola symplocicola Yamam., Trans., Nat. Hist. Soc. Taiwan 31: 57, 1941; Hansford, Sydowia Beih. 2: 519, 1961; Hosag. \& Goos, Mycotaxon 37: 249, 1990; Hosag., Meliolales of India, p. $318,1996$.

Materials examined: On leaves of Symplocos cochinchinensis (Lour.) Moore ssp. laurina (Retz.) Nooteboom (Symplocaceae), Meenmutty forest, Idukki, Kerala, 20.ii.1983, V.B. Hosagoudar HCIO 40564, MH 75875; 20.viii.1983, V.B. Hosagoudar MH 75876; 5.x.1983, V.B. Hosagoudar MH 72162.

Colonies hypophyllous, subdense, velvety, up to $8 \mathrm{~mm}$ in diameter, confluent. Hyphae substraight to flexuous, branching mostly opposite at wide angles, loosely reticulate, cells 18-34 x $6-8 \mu \mathrm{m}$. Appressoria alternate to unilateral, straight to variously curved, antrorse, spreading, 22-26 $\mu \mathrm{m}$ long; stalk cells cylindrical to cuneate, 6-10 $\mu \mathrm{m}$ long; head cells globose, angulose, truncate, variously curved, entire, $12-18$ x 8-12 $\mu \mathrm{m}$. Phialides mixed with appressoria, opposite to alternate, ampulliform, 20-30 x 8-10 $\mu \mathrm{m}$. Mycelial setae grouped around perithecia, straight, simple, acute, very few 2-3 dentate, up to $360 \mu \mathrm{m}$ long. Perithecia scattered, verrucose, up to $200 \mu \mathrm{m}$ in diam.; ascospores 4septate, obovoidal to cylindrical, constricted, $48-59 \times 16-20 \mu \mathrm{m}$.

Host range: Symplocos cochinchinensis

Distribution: Asia

56. Meliola toonae Hosag. \& T. Sabu in Hosag., C.K. Biju \& Abraham, J. Econ. Taxon. Bot.25: 72, 2001.

Materials examined: On leaves of Toona ciliata (Meliaceae), in the campus of TBGRI, Palode, Thiruvananthapuram, Kerala, India, 30.xi.2000, T. Sabu HCIO 43827, TBGT 366.

Colonies amphigenous, mostly epiphyllous, dense, velvety, up to $3 \mathrm{~mm}$ in diameter, confluent. Hyphae straight to substraight, branching alternate to opposite at acute to wide angles, loosely to closely reticulate, cells $24-36$ x 5-7 $\mu \mathrm{m}$. Appressoria alternate, less than $1 \%$ opposite, subantrorse to spreading, straight, 16$24 \mu \mathrm{m}$ long; stalk cells cylindrical to cuneate, $6-10 \mu \mathrm{m}$ long; head cells ovate, oblong to cylindrical, entire, 9-15 x 8-10 $\mu \mathrm{m}$. Phialides mixed with appressoria, alternate to opposite, ampulliform, 16$20 \times 6-8 \mu \mathrm{m}$. Mycelial setae scattered, simple, straight, obtuse to 3-4 times dentate, up to $245 \mu \mathrm{m}$ long. Perithecia scattered to loosely grouped, verrucose, up to $190 \mu \mathrm{m}$ in diameter; ascospores cylindrical, 4-septate, constricted, 40-44 x 12-16 $\mu \mathrm{m}$.

Host range: Symplocos cochinchinensis

Distribution: Asia

\section{REFERENCES}

Hosagoudar, V.B. (1996). Meliolales of India. Botanical Survey of India, Calcutta, $363 \mathrm{pp}$.

Nair, K.K.N. (2000). Manual of Non-Wood Forest Produce Plants of Kerala. KFRI, Peechi, Trissur, Kerala, India, 449pp.

Nayar, M.P., K. Ramamurthy and V.S. Agarwal, (1989). Economic Plants of India. Vol.-I \& II. Botanical Survey of India, Calcutta, 159pp.

\section{ACKNOWLEDGements}

Thanks are due to Dr. S. Ganeshan, Director, TBGRI, Palode for the facilities. I am grateful to Mr. B.V. Shetty, Emeritus Scientist, Mangalore University, Karnataka for reviewing the manuscript critically. 